Manufactured Homes - Probability of Failure and the Need for Better Windstorm Protection Through Improved Anchoring Systems

Richard D. Marshall

Building and Fire Research Laboratory

Gaithersburg, Maryland 20899

QC

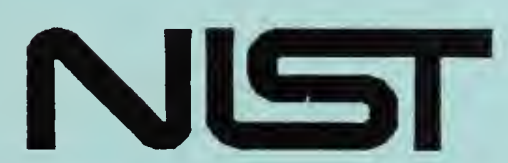

rmitnd States Department of Commerce logy Administration

100

.456

N0. 5370 



\section{Manufactured Homes - Probability of Failure and the Need for Better Windstorm Protection Through Improved Anchoring Systems}

Richard D. Marshall

November 1994

Building and Fire Research Laboratory

National Institute of Standards and Technology

Gaithersburg, MD 20899

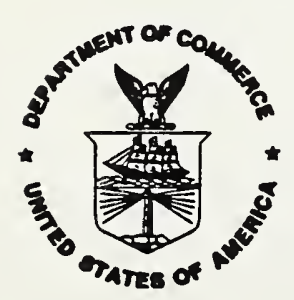

U.S. Department of Commerce

Ronald H. Brown, Secretary

Technology Administration

Mary L. Good, Under Secretary for Technology

National Institute of Standards and Technology

Arati A. Prabhakar, Director
Prepared for:

Department of Housing and Urban Development Washington, DC 20410 



\begin{abstract}
Probabilities of failure are estimated for structures designed in accordance with the wind load provisions of the Manufactured Home Construction and Safety Standards (MHCSS) that were in effect at the time of Hurricane Andrew (1992) and for structures designed in accordance with the wind load provisions of ASCE 7-88 (Minimum Design Loads for Buildings and Other Structures). It is concluded that for a 10-yr exposure the probability of structural failure in a hurricane-prone area such as Dade County, Florida, using the MHCSS wind load criteria is approximately 10 times that determined using the wind load requirements of ASCE 7-88. This same ratio holds for an extra-tropical wind climate such as that of Omaha, Nebraska. For Tucson, Arizona, this ratio is approximately 5. Test data for various components of traditional manufactured home anchoring systems are examined and it is concluded that the load capacity of these systems is substantially less than the load capacities implied by the MHCSS and by current standards covering the installation of manufactured homes. It is recommended that traditional anchoring systems that utilize shallow soil anchors be designed on the basis of factored loads and that preloading be made an integral part of the installation process. A new approach to providing windstorm protection for manufactured homes located in hurricane-prone regions needs to be developed.
\end{abstract}

Keywords: building technology; codes and standards; hurricanes; manufactured homes; mobile homes; natural disasters; soil anchors; structural engineering; wind damage; wind engineering; wind loads; windstorm protection. 


\section{TABLE OF CONTENTS}

ABSTRACT $\ldots \ldots \ldots \ldots \ldots \ldots \ldots \ldots \ldots \ldots \ldots \ldots \ldots \ldots \ldots \ldots \ldots \ldots \ldots$

LIST OF TABLES $\ldots \ldots \ldots \ldots \ldots \ldots \ldots \ldots \ldots \ldots \ldots$

LIST OF FIGURES $\ldots \ldots \ldots \ldots \ldots \ldots \ldots \ldots \ldots \ldots$

NOTATION $\ldots \ldots \ldots \ldots \ldots \ldots \ldots \ldots \ldots \ldots \ldots \ldots \ldots \ldots \ldots \ldots \ldots \ldots \ldots$

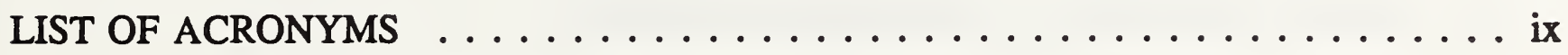

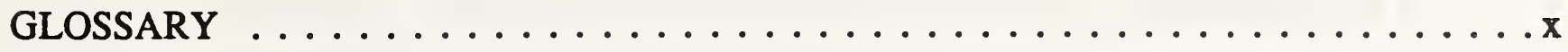

EXECUTIVE SUMMARY $\ldots \ldots \ldots \ldots \ldots \ldots \ldots \ldots \ldots \ldots \ldots \ldots \ldots$. . . . . . .

1.0 INTRODUCTION $\ldots \ldots \ldots \ldots \ldots \ldots \ldots \ldots \ldots \ldots \ldots \ldots \ldots \ldots \ldots \ldots$

2.0 WIND CLIMATE AND PROBABILITY FAILURE $\ldots \ldots \ldots \ldots \ldots$

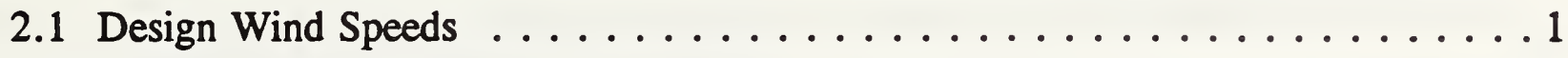

2.2 Probability of Failure $\ldots \ldots \ldots \ldots \ldots \ldots \ldots \ldots \ldots \ldots \ldots \ldots \ldots \ldots \ldots$

3.0 FORCES ON ANCHORING SYSTEMS $\ldots \ldots \ldots \ldots \ldots$

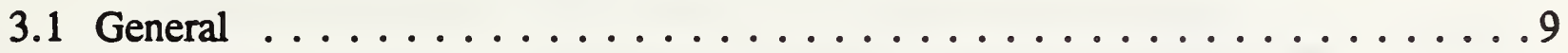

3.2 Nominal Loads . . . . . . . . . . . . . . . . . . . 10

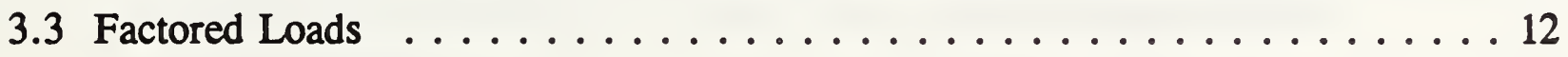

4.0 LOAD CAPACITY OF ANCHORING SYSTEMS $\ldots \ldots \ldots \ldots \ldots$

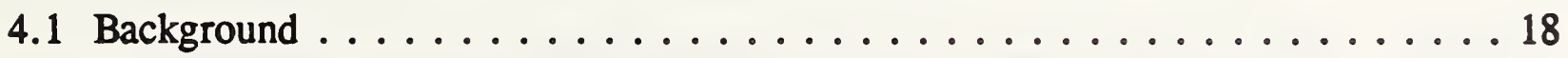

4.2 Steel Strapping . . . . . . . . . . . . . . . . . . 19

4.3 Mechanical Strength of Soil Anchors $\ldots \ldots \ldots \ldots$

4.4 Pull-Out Capacity of Soil Anchors . . . . . . . . . . . . . . 22

4.5 NBS Studies of Soil Anchor Pull-Out Capacity . . . . . . . . . . 26 


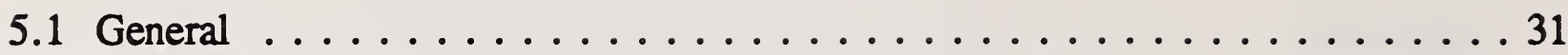

5.2 Shortcomings of the Traditional Approach $\ldots \ldots \ldots \ldots \ldots \ldots$

5.3 A New Approach to Anchor Installation $\ldots \ldots \ldots \ldots \ldots \ldots \ldots$

5.4 Recommended Installation Procedure $\ldots \ldots \ldots \ldots \ldots$

6.0 MAJOR FINDINGS AND RECOMMENDATIONS $\ldots \ldots \ldots \ldots \ldots$

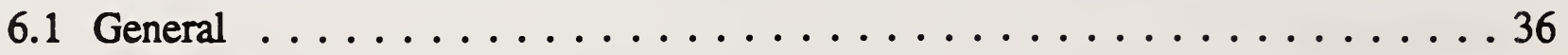

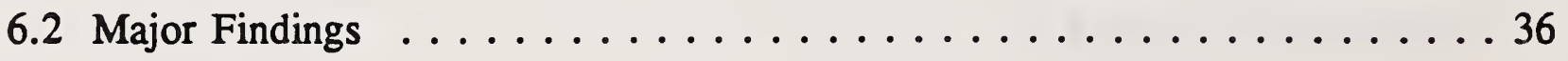

6.3 Recommendations . . . . . . . . . . . . . . . . 37

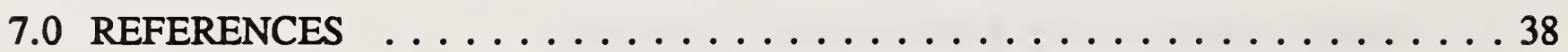

ACKNOWLEDGMENTS $\ldots \ldots \ldots \ldots \ldots \ldots \ldots \ldots \ldots \ldots \ldots \ldots \ldots \ldots \ldots$

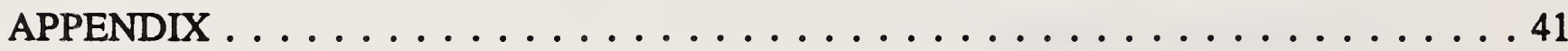

\section{LIST OF TABLES}

Table 1. Probability of Attaining Ultimate Limit State $\ldots \ldots \ldots \ldots \ldots$

Table 2. Nominal and Factored Wind Loads for Single- and Double-Wide Manufactured Homes . . . . . . . . . . . . . . . . . 11

Table 3. Loads per Unit Length of Home Acting on Diagonal Ties and Piers for Typical Single-Wide Manufactured Home . . . . . . . . . . . . 14

Table 4. Effect of Main-Frame Spacing on Diagonal Tie and Pier Loads for Single-Wide and Double-Wide Manufactured Homes . . . . . . . . . 15

Table 5. Results of Laboratory Tension Tests on Cold-Rolled Steel Strapping . . . . . 19

Table 6. Dimensions of Soil Anchors Tested by Pearson et al. . . . . . . . . . . . 21

Table 7. Mechanical Strength of Axially Loaded Soil Anchors . . . . . . . . . . . . 21 
Table 8. Results of Field Pull-Out Tests on Fully Embedded Soil Anchors $\beta_{1}=45$ degrees $\beta_{2}=105$ degrees $\ldots \ldots \ldots \ldots \ldots \ldots \ldots \ldots \ldots \ldots . \ldots \ldots$

Table 9. Results of Field Pull-Out Tests on Fully Embedded Soil Anchors

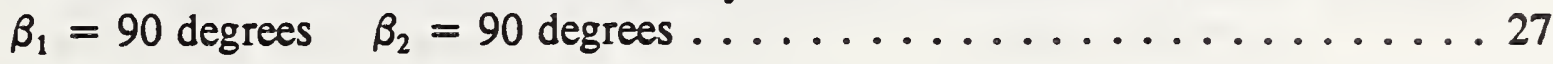

Table 10. Results of Field Pull-Out Tests on Soil Anchors Installed and Loaded at Various Angles . . . . . . . . . . . . . . . . . . 29

\section{LIST OF FIGURES}

Figure 1. Distribution of extreme wind speeds for Dade County, Florida . . . . . . 3

Figure 2. Distribution of extreme wind speeds for Omaha, Nebraska .......... 5

Figure 3. Probability functions for load and resistance, Dade County, Florida . . . . . 7

Figure 4. Typical manufactured home installation schemes $\ldots \ldots \ldots \ldots \ldots$

Figure 5. Tie and pier forces per unit length for a single-wide home and MHCSS Zone I factored wind loads . . . . . . . . . 16

Figure 6. Tie and pier forces per unit length for a single-wide home and factored loads with ASCE 7-88 basic wind speed of $40.2 \mathrm{~m} / \mathrm{s}(90 \mathrm{mph}) \ldots \ldots 17$

Figure 7. Results of laboratory tension tests on cold-rolled steel strapping . . . . . . . 20

Figure 8. Mechanical strength of axially loaded soil anchors . . . . . . . . . . 22

Figure 9. Definition sketch showing soil anchor orientation and angle

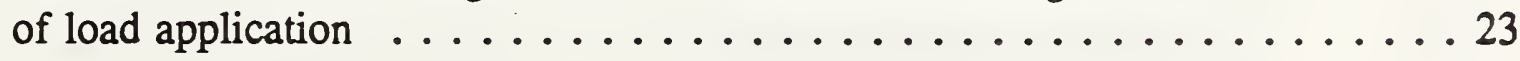

Figure 10. Limiting displacements and shape of deformed soil anchor . . . . . . . 23

Figure 11. Typical soil anchor with stabilizer plate $\ldots \ldots \ldots \ldots . \ldots . \ldots 24$

Figure 12. Anchor pull-out capacities. $\beta_{1}=45$ degrees $\beta_{2}=105$ degrees $\ldots . .25$

Figure 13. Typical load-displacement characteristics for fully embedded soil anchors in silt, sand and clay. $\beta_{1}=90$ degrees $\beta_{2}=90$ degrees $\ldots \ldots \ldots 27$

Figure 14. Results of field pull-out tests on fully embedded soil anchors. $\beta_{1}=90$ degrees $\beta_{2}=90$ degrees $\ldots \ldots \ldots \ldots \ldots \ldots \ldots \ldots$ 
Figure 15. Typical load-displacement characteristics for fully embedded soil anchors in silt, sand and clay. $\beta_{1}=40$ degrees $\beta_{2}=90$ degrees $\ldots \ldots \ldots 29$

Figure 16. Results of field pull-out tests on soil anchors installed and loaded

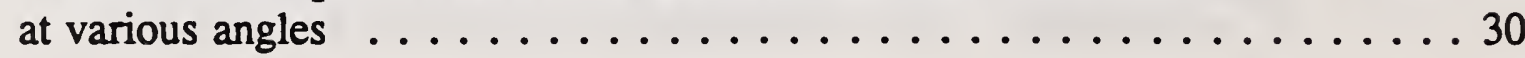

Figure 17. Correlation between SPT blow count and STP torque reading for silty soil . . 32

Figure 18. Correlation between STP torque reading and withdrawal resistance of fully embedded soil anchors. $\beta_{1}=90$ degrees $\beta_{2}=90$ degrees $\ldots \ldots 32$

Figure 19. Inclined pull-out test on a fully embedded single-helix anchor in sand. $\beta_{1}=40$ degrees $\beta_{2}=90$ degrees $\ldots \ldots \ldots \ldots \ldots \ldots \ldots \ldots \ldots \ldots \ldots \ldots \ldots$

Figure 20. Scheme proposed by Yokel et al. for the preloading of vertically installed soil anchors with inclined loads $\ldots \ldots \ldots \ldots \ldots \ldots$

\section{NOTATION}

The following symbols are used in this report:

COV Coefficient of variation

D Dead load

L Live load, load effect

$\mathrm{N} \quad$ Exposure period in years

$\mathrm{P}_{\mathrm{L}}(\mathrm{x}) \quad$ Probability that $\mathrm{L}<\mathrm{x}$

$P_{f} \quad$ Annual probability of failure

$\mathrm{P}_{\mathrm{f}(\mathrm{N})} \quad$ Probability of failure during $\mathrm{N}$-yr exposure period

$P_{W} \quad$ Drag load

$P_{R L} \quad$ Uplift load on leeward roof

$\mathrm{P}_{\mathrm{RW}} \quad$ Uplift load on windward roof

$P_{2 v} \quad$ Applied load at $25.4 \mathrm{~mm}$ (2 in.) vertical displacement

$\mathrm{Q}_{\mathrm{L}}(\mathrm{x}) \quad$ Probability that $\mathrm{L} \geq \mathrm{x}$

$Q_{u} \quad$ Anchor pull-out capacity

$\mathbf{R} \quad$ Structural resistance or strength

$\mathbf{R}_{\mathrm{L}} \quad$ Leeward pier reaction

$\mathbf{R}_{\mathbf{w}} \quad$ Windward pier reaction

$T_{D} \quad$ Force in windward diagonal tie

$T_{L} \quad$ Force in leeward vertical tie

$\mathrm{T}_{\mathrm{W}} \quad$ Force in windward vertical tie

$\mathrm{U}_{\mathrm{FM}} \quad$ Fastest-mile wind speed

$U_{\mathrm{N}} \quad$ Wind speed associated with $\mathrm{N}$-yr mean recurrence interval

$\mathrm{U}_{50} \quad$ Wind speed associated with 50-yr mean recurrence interval 


$\begin{array}{ll}\text { W } & \text { Wind load } \\ \mathrm{a} & \text { Main-frame spacing } \\ \mathrm{b} & \text { Width of manufactured home } \\ \mathrm{h} & \text { Net height (box height) of manufactured home } \\ \mathrm{p}_{\mathrm{R}}(\mathrm{x}) & \text { Probability density function of resistance } \\ \mathrm{q} & \text { Reference dynamic pressure } \\ \mathrm{x} & \text { Load variable } \\ \beta_{1} & \text { Angle of applied load (from horizontal) } \\ \beta_{2} & \text { Angle of installed soil anchor (from horizontal) } \\ \gamma & \text { Load factor } \\ \phi & \text { Resistance factor }\end{array}$

\section{LIST OF ACRONYMS}

ANSI American National Standards Institute

ASCE American Society of Civil Engineers

ASD Allowable stress design

CDF Cumulative distribution function

HUD Department of Housing and Urban Development

LRFD Load and resistance factor design

MHCSS Manufactured Home Construction and Safety Standards

MRI Mean recurrence interval

NCSBCS National Conference of States on Building Codes and Standards

NIST National Institute of Standards and Technology

PDF Probability density function

SFBC South Florida Building Code

SPT Standard penetration test

STP Soil test probe 


\section{GLOSSARY}

Allowable stress design: a method of proportioning structures such that the computed elastic stress does not exceed a specified limiting stress. Also called working stress design.

Anchoring system: the combination of ties and soil anchors which provides stability for manufactured homes.

Axial load: load applied in line with the axis of a soil anchor.

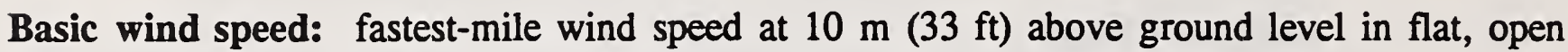
country and having an annual probability of 0.02 of being equaled or exceeded.

Central factor of safety: a factor obtained by dividing the mean resistance by the mean load effect.

Coefficient of variation: the ratio of the standard deviation to the mean of a random variable.

Cone of influence: the volume of soil activated during anchor withdrawal, generally assumed to be conical in shape with the surface at 45 degrees to the anchor shaft.

Dead load: load due to structural self-weight and the permanent features of a building.

Diagonal tie: the link between the manufactured home and a soil anchor which primarily resists sliding forces.

Drag load: wind-induced load acting on a structure in the direction of the wind.

Exposure category: classification that reflects the characteristics of ground surface irregularities upwind of a building or other structure.

Factor of safety: a factor by which a designated limit state force or stress is divided to obtain a specified allowable value.

Factored load: the product of the nominal load and a load factor.

Fastest-mile speed: the wind speed averaged over the time required for a mile-long volume of air to pass a fixed point.

Helix plate: circular plate attached to the shaft of a soil anchor to facilitate installation and to provide withdrawal resistance.

Importance factor: a factor that accounts for the degree of hazard to human life and damage to property. 
Inclined load: load applied at some angle to the axis of a soil anchor.

Limit states: criteria beyond which a structure or structural element is judged to be no longer useful for its intended function (serviceability limit state) or beyond which it is judged to be unsafe (ultimate limit state).

Live load: the load superimposed on a structure by use and occupancy of the structure.

Load and resistance factor design: a design method which uses load and resistance factors in the design format.

Load effect: the force in a member or an element (axial force, shear force, bending moment, torque) due to the loading.

Load factor: a frctor that accounts for unavoidable deviations of the actual load from the nominal value an e uncertainties in the analysis that transforms the load into a load effect.

Main frame: that part of the manufactured home structural system which transmits accunulative design loads to the support system.

Main-frame spacing: distance between the primary longitudinal members of the main frame of a manufactured home.

Mean recurrence interval: the number of years, on average, between events of like magnitude or intensity.

Nominal load: load specified by a code or standard; usually defined with reference to some probability of being exceeded.

Nominal resistance: the resistance or load capacity of a structure or component as determined by using nominal material and cross-sectional properties and a rationally developed formula based on an analytical and/or experimental model of limit state behavior.

Pier: that portion of the support system between the footing and the manufactured home, exclusive of caps and shims.

Probability distribution: a mathematical law which describes the probability that a random variable will assume certain values; either the cumulative distribution function (CDF) or the probability density function (PDF) is used.

Reloading modulus: the ratio of the applied load to displacement upon reloading, where the applied load is 85 percent of the highest load attained prior to unloading.

Resistance: the maximum load carrying capacity as defined by a limit state. 
Resistance factor: a factor by which the nominal resistance is multiplied to account for the uncertainties in its determination.

Soil anchor: a device which is either driven or screwed into the ground and to which vertical and/or diagonal ties are attached.

Stabilizer plate: a component of an anchoring system intended to provide lateral support to the shaft of a soil anchor.

Strapping: material or securing device used to connect a manufactured home to soil anchors.

Structural stability: resistance to being displaced by a force or combination of forces.

Support system: a combination of footings, piers, caps and shims that supports the manufactured home.

Uplift load: wind-induced load acting on a structure in the vertical direction.

Vertical tie: the link between the manufactured home and a soil anchor which resists uplift loads. 


\section{EXECUTIVE SUMMARY}

This report describes a continuation of earlier studies carried out by the National Institute of Standards and Technology (NIST) at the request of the Department of Housing and Urban Development (HUD) following the devastation caused by Hurricane Andrew in south Florida on August 24, 1992. In the earlier work, damage to manufactured homes was examined in light of the probable maximum wind speeds in the affected area, and the wind load provisions of selected codes and standards used for structural design in hurricane-prone regions were compared. On the basis of that work, it was recommended that ASCE 7-88 (Minimum Design Loads for Buildings and Other Structures) should be the primary resource document for updating and improving the wind load provisions of the Manufactured Home Construction and Safety Standards (MHCSS).

To establish points of reference, probabilities of structural failure (defined as attaining an ultimate limit state) are obtained for three extreme wind climates in the United States using the wind load provisions of the MHCSS that were in effect at the time of Hurricane Andrew and using the provisions of ASCE 7-88 in the context of load and resistance factor design (LRFD) as opposed to allowable stress design (ASD). A load factor of 1.3 is assumed for wind effects and it is assumed that the mean structural resistance can be characterized by a resistance factor of 0.8 and a coefficient of variation of 0.10 . For a 10 -yr exposure the probability of structural failure in a hurricane-prone area such as Dade County, Florida, using the MHCSS wind load criteria is approximately 10 times that determined using the wind load requirements of ASCE 7-88. This same ratio holds for an extra-tropical wind climate such as that for Omaha, Nebraska. For Tucson, Arizona, this ratio is approximately 5.

Because test data on which to base an LRFD design approach are more readily available for anchoring systems than they are for manufactured home systems and components, this study concentrates on the former. It was found that the load capacities of anchoring components assumed by the MHCSS, by ANSI A225.1-1982 (Manufactured Home Installations), and by NCSBCS A225.1-1987 are not supported by available test data. Rather than the ultimate strength of $21.02 \mathrm{kN}(4,725 \mathrm{lbf})$ assumed by these standards for cold-rolled steel strapping, the actual capacity of installed strapping appears to be no greater than about $16.90 \mathrm{kN}(3,800 \mathrm{lbf})$. And although the mechanical strength of axially loaded soil anchors does not appear to be a limiting factor, their pull-out resistance and stiffness under inclined loads fall far short of the stated requirements. For example, using accepted installation practice, soil anchors installed in loose to medium dense sand and subjected to inclined loads develop approximately 26 percent of the resistance required by ANSI A225.1-1982 at a limiting horizontal displacement of $102 \mathrm{~mm}$ (4 in.), even when equipped with stabilizer plates. At maximum applied load and corresponding horizontal displacements of the order of 250 to $500 \mathrm{~mm}$ (10 to $20 \mathrm{in}$.), these same anchors developed only about 80 percent of the required minimum working load of $14.01 \mathrm{kN}(3,150 \mathrm{lbf})$.

Pull-out tests on vertically installed anchors without stabilizer plates in silt, sand and clay developed resistances that ranged from 3.41 to $13.20 \mathrm{kN}(767$ to $2,967 \mathrm{lbf})$ at a limiting horizontal displacement of $102 \mathrm{~mm}$ (4 in.) when subjected to inclined loads applied at angles 
ranging from 40 to 60 degrees. The corresponding ultimate load capacities ranged from 14.53 to $35.29 \mathrm{kN}(3,267$ to $7,933 \mathrm{lbf})$. The large horizontal displacements required to develop acceptable levels of anchor resistance are incompatible with the displacement limits needed to ensure pier stability. However, by preloading soil anchors under the action of inclined loads, the horizontal displacements are greatly reduced, and pier instability is not a major concern.

It has been suggested that the current practice of installing vertical ties to act in combination with diagonal (frame) ties can be effective in forestalling separation of the roof structure from the walls of a manufactured home in high winds. However, this argument has little merit when short vertical ties are used and are attached only to the wall studs. Furthermore, analyses of loads and reactions presented in this report indicate that vertical ties are largely ineffective in resisting wind loads when diagonal ties are installed at angles of approximately 45 degrees. Finally, it has been observed that protective coatings currently used for soil anchors are inadequate since most of the coating is either damaged or completely removed during anchor installation.

If the traditional approach to providing windstorm protection by means of steel strapping and shallow soil anchors is to continue, it is recommended that the design of such systems be based on factored loads and that all anchors be preloaded following installation. Anchors should be installed vertically to obtain maximum depth of the helix plate, and the anchor should be preloaded to function with a single diagonal frame tie rather than with a combination of vertical and diagonal ties. The principal advantages of preloading are that the uncertainties inherent in the standard penetration test (SPT) and the soil test probe (STP) are no longer significant; it becomes possible to utilize the higher pull-out capacities of vertically installed anchors loaded at an angle; the anchor stiffness is increased significantly; and stabilizing devices such as steel plates that have been shown to be of limited effectiveness may not be required.

Although the performance of conventional soil anchors can be improved significantly through preloading, it does not appear that this traditional approach to windstorm protection will prove to be workable for basic wind speeds in excess of about $44.7 \mathrm{~m} / \mathrm{s}(100 \mathrm{mph})$. For wind speeds above this level, a new approach to windstorm protection of manufactured homes is needed. 


\subsection{INTRODUCTION}

Following the devastation caused by Hurricane Andrew in Dade County, Florida, on August 24, 1992, the Department of Housing and Urban Development (HUD) requested the National Institute of Standards and Technology (NIST) to undertake a review of the wind load provisions of the Manufactured Home Construction and Safety Standards (MHCSS 1992). Findings and recommendations resulting from that review are contained in NIST Interagency Report 5189 (Marshall 1993). The observed damage to manufactured homes located in the area affected by Hurricane Andrew's strongest winds was compared with the probable maximum surface wind speeds, and the wind load requirements of the MHCSS were compared with those of other contemporary codes and standa ds used for structural design in hurricane-prone regions. It was concluded that ASCE 7-88 (Minimum Design Loads for Buildings and Other Structures) should be the basis for updating the wind load requirements of the MHCSS.

On January 14, 1994, the Department of Housing and Urban Development amended the Federal Manufactured Home Construction and Safety Standards (HUD 1994). Briefly, this amendment establishes wind Zones II and III for which the basic wind speeds are 44.7 and $49.2 \mathrm{~m} / \mathrm{s}$ (100 and $110 \mathrm{mph}$ ), respectively. In addition, the required design pressures for these zones have been revised to reflect the corresponding ASCE 7-88 wind load requirements. The design requirements for areas not included in Zones II and III remain unchanged. The rule change was to become effective on July 13, 1994.

The work described herein assesses the probability of structural failure associated with the MHCSS wind load criteria in effect at the time of Hurricane Andrew and with the wind load provisions of ASCE 7-88 for selected extreme wind climates. The resistance side of the design equation is examined in the context of traditional anchoring systems whose function is to provide adequate windstorm protection for manufactured homes. Recommendations are developed for a new approach to the design and installation of these systems.

\subsection{WIND CLIMATE AND PROBABILITY OF FAILURE}

\subsection{Design Wind Speeds}

Design wind speeds should reflect the local wind climate (distribution of extremes) and the consequences of str ctural failure. For ordinary buildings and structures, it is generally accepted that the design wind loads should have as their basis the wind speeds associated with a mean recurrence interval (MRI) of about 50 years. Although the probability that these speeds will be exceeded in a 50-vr period is relatively high (0.64), the use of load and resistance factors or allowable stresses in the design process reduces the risk of a structural failure to about 5 percent over the same interval (Gupta and Moss 1993). Estimation of the 50-yr wind for a given location involves the statistical analysis of the annual extremes observed at that location. For reliable estimates, the series of annual extremes should consist of at least 30 years of record. 
Hurricanes present a special problem because of their relatively low frequency of occurrence and because of the difficulties in obtaining reliable wind speed measurements under hurricane conditions. To circumvent this problem, Monte Carlo techniques employing certain climatological and physical models are used to generate a large number of artificial hurricane events affecting a given location. The resulting series of extremes is the basis for estimating the cumulative distribution function (CDF). This procedure was developed by Russell (1971) and has been further developed and applied by Batts et al. (1980) and by Georgiou et al. (1983) to obtain estimates of hurricane wind speeds along the Gulf and Atlantic Coasts of the United States.

\section{Dade County, Florida:}

Figure 1 shows a relationship between wind speed and mean recurrence interval for the coastal area directly south of Miami, Florida, based on the work of Georgiou et al. (1983). The wind speeds are fastest-mile speeds at a height of $10 \mathrm{~m}(33 \mathrm{ft})$ in a category $\mathrm{C}$ wind exposure as defined by ASCE 7-88. The maximum fastest-mile wind speeds over land in Hurricane Andrew are believed to have ranged from 54.5 to $64.8 \mathrm{~m} / \mathrm{s}$ (122 to $145 \mathrm{mph}$ ) in the area of heaviest structural damage (Reinhold et al. 1992). From Figure 1, the corresponding mean recurrence intervals (MRI) range from approximately 75 to 300 years (annual probabilities of 0.013 to 0.003 ). Note that the annual probability of the wind speeds being equaled or exceeded is simply the reciprocal of the mean recurrence interval in years.

MHCSS in Figure 1 corresponds to the design wind speed of $35.8 \mathrm{~m} / \mathrm{s}$ ( $80 \mathrm{mph})$ implied by the manufactured home lift and drag load requirements that were in effect at the time of Hurricane Andrew (Marshall 1993). SFBC in Figure 1 denotes the equivalent fastest-mile design speed of $42.5 \mathrm{~m} / \mathrm{s}$ ( $95 \mathrm{mph}$ ) implied by the South Florida Building Code (SFBC 1988). Although the SFBC specifies a design wind speed of $53.6 \mathrm{~m} / \mathrm{s}(120 \mathrm{mph})$, this speed is, in effect, a gust speed as gust response factors are not included in the SFBC wind load provisions. Also shown in Figure 1 are the design wind speeds of 51.6 and $49.2 \mathrm{~m} / \mathrm{s}(116$ and $110 \mathrm{mph}$ ) required by ASCE 7-88 for structural categories I and IV, respectively (I = ordinary buildings, IV = agricultural buildings). The ASCE 7-88 design speeds are obtained by multiplying the basic (50-yr) wind speed of $49.2 \mathrm{~m} / \mathrm{s}(110 \mathrm{mph})$ by the appropriate importance factor. Note that the ASCE 7-88 basic wind speed for Dade County corresponds to a mean recurrence interval of slightly more than 40 years in the analysis carried out by Georgiou et al. (1983). It can be seen from Figure 1 that the MHCSS and SFBC design wind speeds fall well below the ASCE 7-88 requirements, including the design wind speed for agricultural buildings.

Load and resistance factor design (LRFD) requires that

$$
\phi \mathrm{R} \geq \gamma \mathrm{L}
$$

where $\mathrm{R}$ is the nominal resistance, $\mathrm{L}$ is the nominal load effect, and $\phi$ and $\gamma$ are factors that account for the uncertainties associated with resistance and load effect, respectively. Standards such as ASCE 7-88 provide values of $\gamma$ for various types of loads and load combinations while 


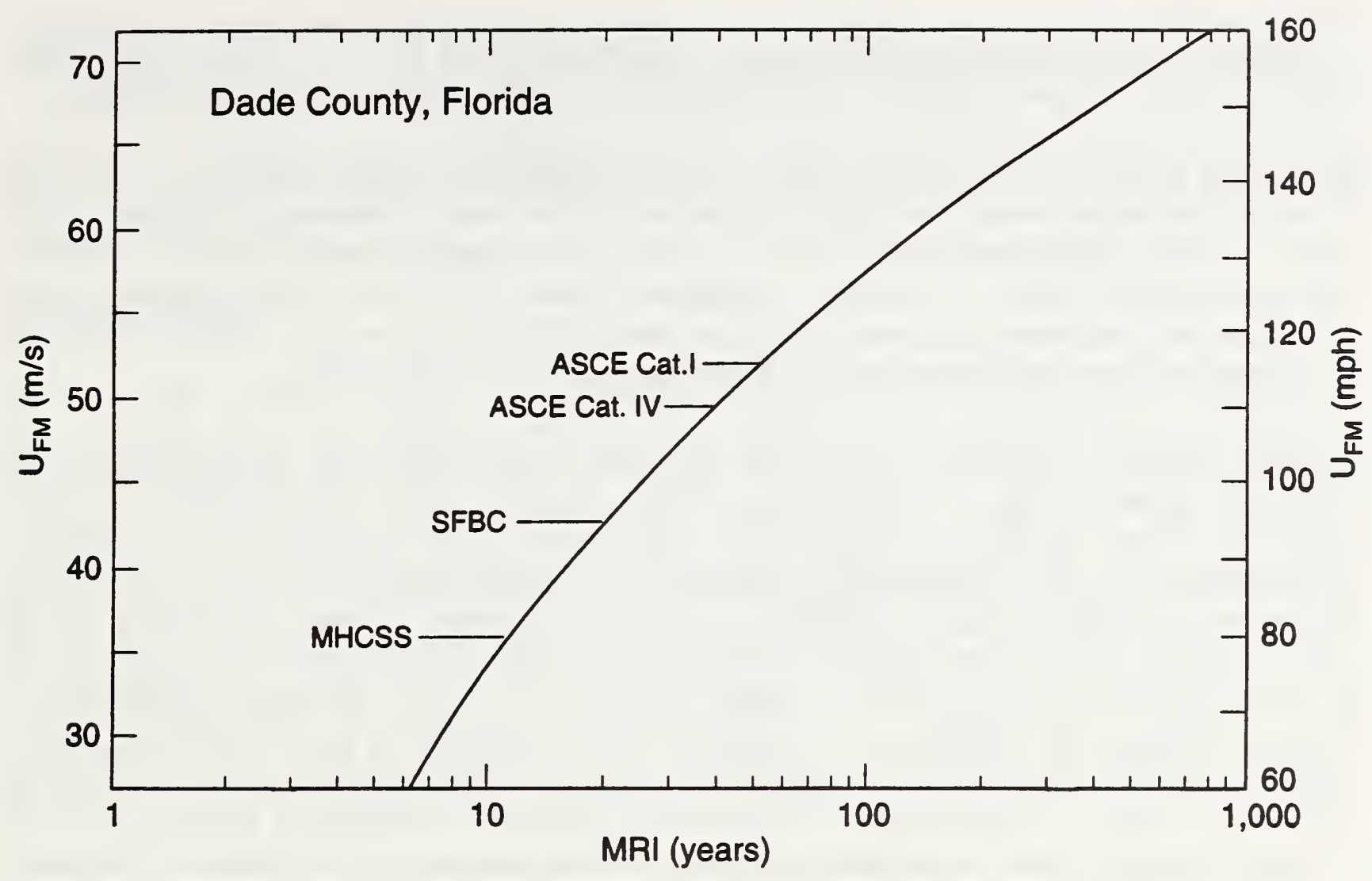

Figure 1. Distribution of extreme wind speeds for Dade County, Florida (Based on analysis by Georgiou et al. 1983)

recommended values of $\phi$ are provided in materials specifications and standards intended for use with the LRFD format. For wind loading of a manufactured home superstructure (box), dead load and wind load constitute the critical load combination and ASCE 7-88 requires that

$$
\phi R \geq 0.9 \mathrm{D}+1.3 \mathrm{~W}^{1}
$$

where $\mathrm{D}$ and $\mathrm{W}$ denote the nominal (code value) dead and wind load, respectively. Implicit in the load factor of 1.3 is a reduction factor of 0.85 to account for the reduced probability that the maximum wind speed will occur for a wind direction that is most unfavorable to the building response (Ellingwood et al. 1980). Due to the fact that many material design standards include a 1/3 increase in allowable stresses for wind loading, ASCE 7-88 does not apply the 0.85 reduction factor to wind loads for use in allowable stress design (ASD). Because wind loads vary as the square of the wind speed, the ASCE 7-88 factored wind loads correspond to the wind speeds indicated in Figure 1, multiplied by $(1.3)^{1 / 2}=1.14$. Thus, the factored wind load for

${ }^{1}$ The actual form of the load combination is $0.9 \mathrm{D}-1.3 \mathrm{~W}$ to emphasize the fact that these are counteracting loads. 
a category I structure would correspond to a wind speed of $51.6 \times 1.14=58.8 \mathrm{~m} / \mathrm{s}(132 \mathrm{mph})$, an event that would be expected in Dade County about once every 130 years on average.

If the dead load effect can be neglected, it is then possible to estimate a reference wind speed at which the factored wind load equals the nominal (unfactored) resistance. Resistance factors used in LRFD typically range from 0.7 to 0.9 when the nominal resistance and mean resistance are approximately equal. Assuming a resistance factor of 0.8 , the mean resistance would correspond to a reference wind speed of approximately $58.8 /(0.8)^{1 / 2}=65.7 \mathrm{~m} / \mathrm{s}(147 \mathrm{mph})$, and the associated mean recurrence interval from Figure 1 is about 325 years.

For the MHCSS wind load criteria and allowable stress design, the corresponding mean resistance is not known with certainty. Values of $\phi$ for light wood framing are under development and are not generally available for various other materials and components commonly used in manufactured home construction. For engineered wood components such as glulam beams, Ellingwood et al. (1980) have shown that the ratio of mean to nominal resistance based on linear working stress design principles is about 1.80, allowing for a 33 percent increase in resistance when wind constitutes the major load effect. However, as noted by Ellingwood et al., light frame wood structures are not designed in the same sense as, for example, steel or reinforced concrete structures. Structural assemblies use dimension lumber repetitiously and, therefore, statistics on the strength of individual specimens of dimension lumber are not an entirely satisfactory basis for reliability analysis. It is the statistics on the resistance of structural assemblies such as roof trusses, floor and ceiling diaphragms, shear walls, and the connections between these structural assemblies that are needed. Unfortunately, there are insufficient test data on these assemblies and connections to estimate probability distributions and coefficients of variation.

As an alternative to engineering analysis, the MHCSS prescribes proof load and ultimate load tests for structural assemblies. The proof load test requires that structural assemblies be capable of sustaining their dead load plus 1.75 times the specified design live load (defined in the MHCSS to mean occupancy, wind or snow loads) without failure. Ultimate load tests for roof trusses require the dead load plus 2.50 times the design live load to be resisted without failure. Limited testing of typical ceiling diaphragm construction used in manufactured homes has shown the ratio of mean to nominal resistance based on linear working stress design principles to be about 2.6 (NAHB 1988). Similar tests on metal roof assemblies and their connections have shown this ratio to be about 2.7 (Dewey and Luebs 1992). However, this same ratio, when based on the nominal strength of fastener schedules used by a sample of 23 manufacturers, ranges from 0.9 to 4.8 . The estimation of mean resistance is further complicated by the fact that numerous failure modes are possible in a complete home, and some of these failure modes under wind loading can have their origin in the failure of nonstructural elements such as the building envelope (roofing, cladding, glazing, etc.). If a value of 2.0 for the ratio of mean to nominal resistance is taken as being representative of manufactured home construction, then the reference wind speed corresponding to the mean resistance of homes sited in exposure category $\mathrm{C}$ would be $(2.0)^{1 / 2}$ times the basic wind speed, or $(1.414)(35.8)=50.6 \mathrm{~m} / \mathrm{s}(113 \mathrm{mph})$ for "hurricane resistive" construction. Accordingly, the distribution of extreme speeds shown in Figure 1 
suggests that widespread failure of manufactured homes designed in accordance with the MHCSS wind load provisions in effect at the time of Hurricane Andrew and located in exposure category $\mathrm{C}$ in Dade County could be expected about every 50 years on average. It is of interest to note that the wind speeds at which HUD-labeled units in Hurricane Andrew began to experience significant structural damage are believed to have ranged from 44.7 to $53.6 \mathrm{~m} / \mathrm{s}$ (100 to 120 mph) (Marshall 1993).

\section{Omaha, Nebraska:}

Extreme wind speeds at Omaha, Nebraska (and the midwest in general), are associated with extra-tropical storms that include well-developed winter storms and summer thunderstorms which, on occasion, spawn tornadoes. While the wind load provisions of ASCE 7-88 do not explicitly account for the effects of tornadoes, it happens that a large percentage of the area affected by a given tornado actually experiences wind speeds that are less than the basic wind speeds prescribed by ASCE 7-88. The distribution of speeds shown in Figure 2 is derived from the series of annual extremes for Omaha observed over a period of 42 years (Simiu et al. 1979). The design speed of $29.1 \mathrm{~m} / \mathrm{s}(65 \mathrm{mph})$ implied by the MHCSS lift and drag loads for Zone I and the design wind speeds of $37.1 \mathrm{~m} / \mathrm{s}(83 \mathrm{mph})$ and $(37.1)(0.95)=35.2 \mathrm{~m} / \mathrm{s}(79 \mathrm{mph})$ specified by ASCE 7-88 for category I and IV structures, respectively, are shown in Figure 2. Note that the MHCSS design speed corresponds to a mean recurrence interval of about 7 years.

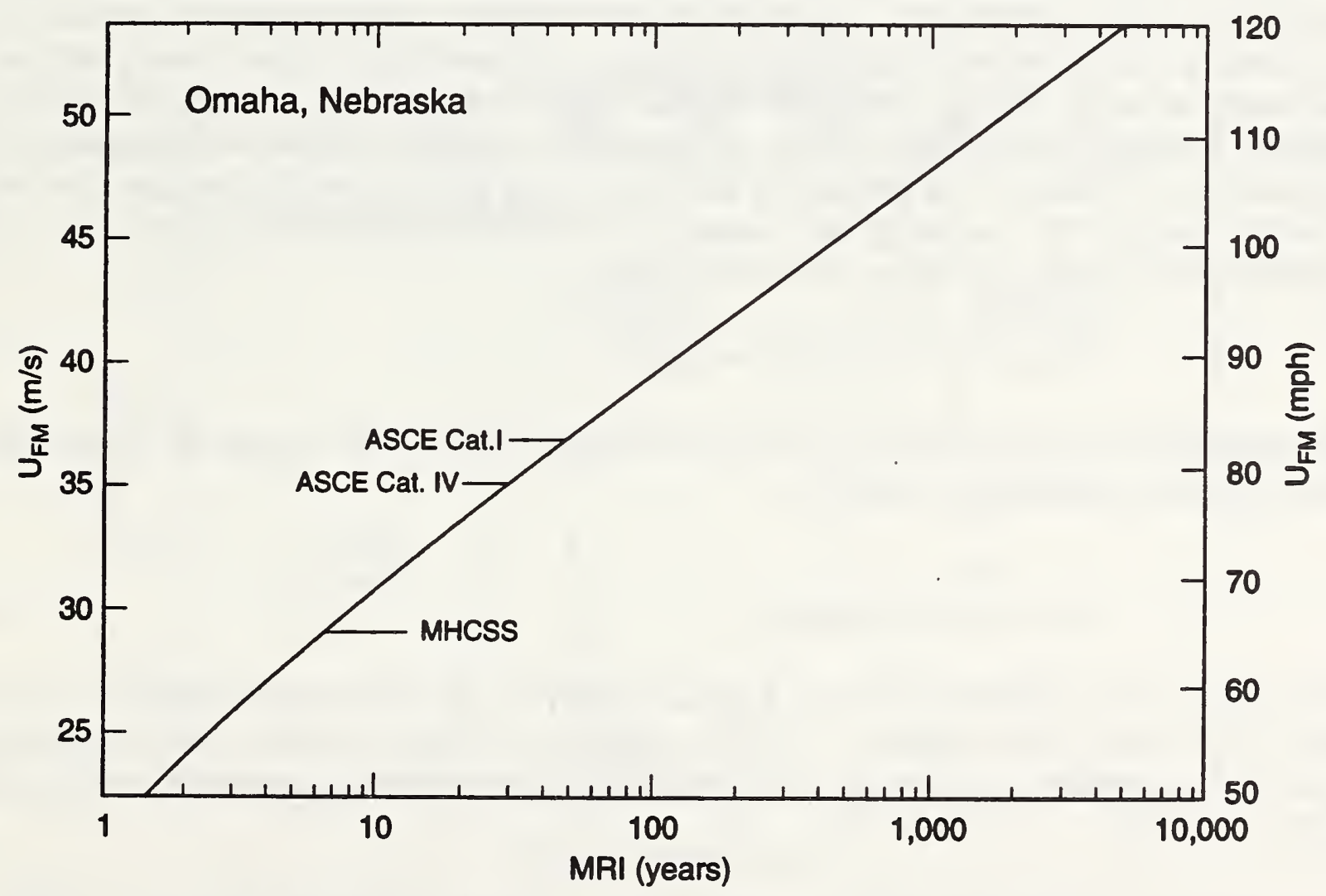

Figure 2. Distribution of extreme wind speeds for Omaha, Nebraska (Based on analysis by Simiu et al. 1979) 
The factored wind load for a category I structure sited in a category $\mathrm{C}$ exposure corresponds to a wind speed of $37.1 \times(1.3)^{1 / 2}=42.3 \mathrm{~m} / \mathrm{s}(95 \mathrm{mph}$ ), and the nominal (unfactored) resistance would correspond to a wind speed of $42.3 /(0.8)^{1 / 2}=47.3 \mathrm{~m} / \mathrm{s}(106 \mathrm{mph})$. In terms of mean recurrence interval, widespread failures of buildings and other structures designed in accordance with the requirements of ASCE 7-88 would be expected at intervals of about 900 years on average. For manufactured homes with a ratio of mean to nominal resistance of 2.0 , the wind speed corresponding to the mean resistance would be $(1.414)(29.1)=41.1 \mathrm{~m} / \mathrm{s}(92 \mathrm{mph})$. The corresponding mean recurrence interval is about 160 years. Given the design wind speed of $35.8 \mathrm{~m} / \mathrm{s}(80 \mathrm{mph})$ for the so-called "hurricane resistive" manufactured homes, it would seem more appropriate to have marketed these units in Nebraska as opposed to south Florida.

\subsection{Probability of Failure}

Generally, the available information from which to estimate the probability of failure of a building or other structure is very limited. Nevertheless, it is useful to examine the relative risk associated with various design requirements and extreme wind environments. In the following, probabilities of failure implicit in the current MHCSS wind load requirements are compared with those of ASCE 7-88 for selected locations in the United States.

Let $\mathrm{L}$ denote some external load on a structure that results in certain structural actions such as axial force, flexure, shear, etc. Let $R$ denote the strength or resistance of the structure, i.e., the external load acting on the structure at failure. As used here, failure corresponds to the attainment of some ultimate limit state beyond which the structure or structural element in question is judged to be unsafe. Thus, by definition, a failure condition exists whenever the inequality $L \geq R$ holds. The probability that the external load, $L$, will be less than some value $x$ can be obtained by evaluating the cumulative distribution function (CDF) of $L$ at $x$. The probability of $x$ being equaled or exceeded is then

$$
P(L \geq x)=1-P_{L}(x)=Q_{L}(x)
$$

The probability that the resistance, $R$, will be between $x$ and $x+d x$ is $p_{R}(x) d x$, and it follows that the annual probability of failure is

$$
P_{f}=\int_{0}^{\infty} Q_{L}(x) p_{R}(x) d x
$$

where $p_{R}(x)$ is the probability density function (PDF) for the structural resistance. For wind load, the external load variable, $x$, can be replaced by some reference dynamic pressure $q$ which, for convenience, is taken to be the reference dynamic pressure associated with the $\mathrm{N}$-yr wind speed $U_{N}$.

The probability that failure will not occur during an exposure period of $N$ years is $\left(1-P_{f}\right)^{N}$. It follows that the probability of attaining a failure condition at least once during an $\mathrm{N}$-year exposure is 


$$
P_{f(M)}=1-\left(1-P_{f}\right)^{N}
$$

The forms of the cumulative distribution function (CDF) for wind load and of the probability density function (PDF) for strength or resistance are not known exactly, but a reasonable assumption is that structural resistance is normally distributed. Studies of the distribution of dynamic pressure reported by Cook (1985) suggest that a Type I distribution provides a reasonable fit to the series of annual extremes. This same distribution has been used for wind load in calculating $\mathrm{P}_{\mathrm{f}}$.

Probabilities of attaining or exceeding an ultimate limit state in a category $\mathrm{C}$ exposure were calculated for Dade County Florida; Omaha, Nebraska; and Tucson, Arizona. It was assumed that $\phi=0.8, \gamma_{\mathrm{w}}=1.3$, and coefficient of variation $\mathrm{COV}=0.1$ for structural resistance. Implicit in the MHCSS wind load requirements are basic wind speeds of 29.1 and $35.8 \mathrm{~m} / \mathrm{s}(65$ and $80 \mathrm{mph}$ ) for Zones I (non-hurricane) and II (hurricane), respectively (Marshall 1993). According to ASCE 7-88, the basic wind speeds for Dade County, Omaha and Tucson are 49.2, 37.1 and $33.5 \mathrm{~m} / \mathrm{s}(110,83$ and $75 \mathrm{mph})$, respectively. The function $\mathrm{Q}_{\mathrm{L}}(q)$ for load and the functions $p_{R}(q)$ for resistance are shown in Figure 3 for Dade County, Florida. Note that in Figure 3 the probabilities for resistance are plotted against a reference dynamic pressure rather than a reduced variate to better illustrate their relationship to the load effect. Values of $P_{f}$ were obtained from Eq. 4 by numerical integration and values of $P_{\mathrm{fN}}$ (see Eq. 5 ) for various exposure periods are listed in Table 1.

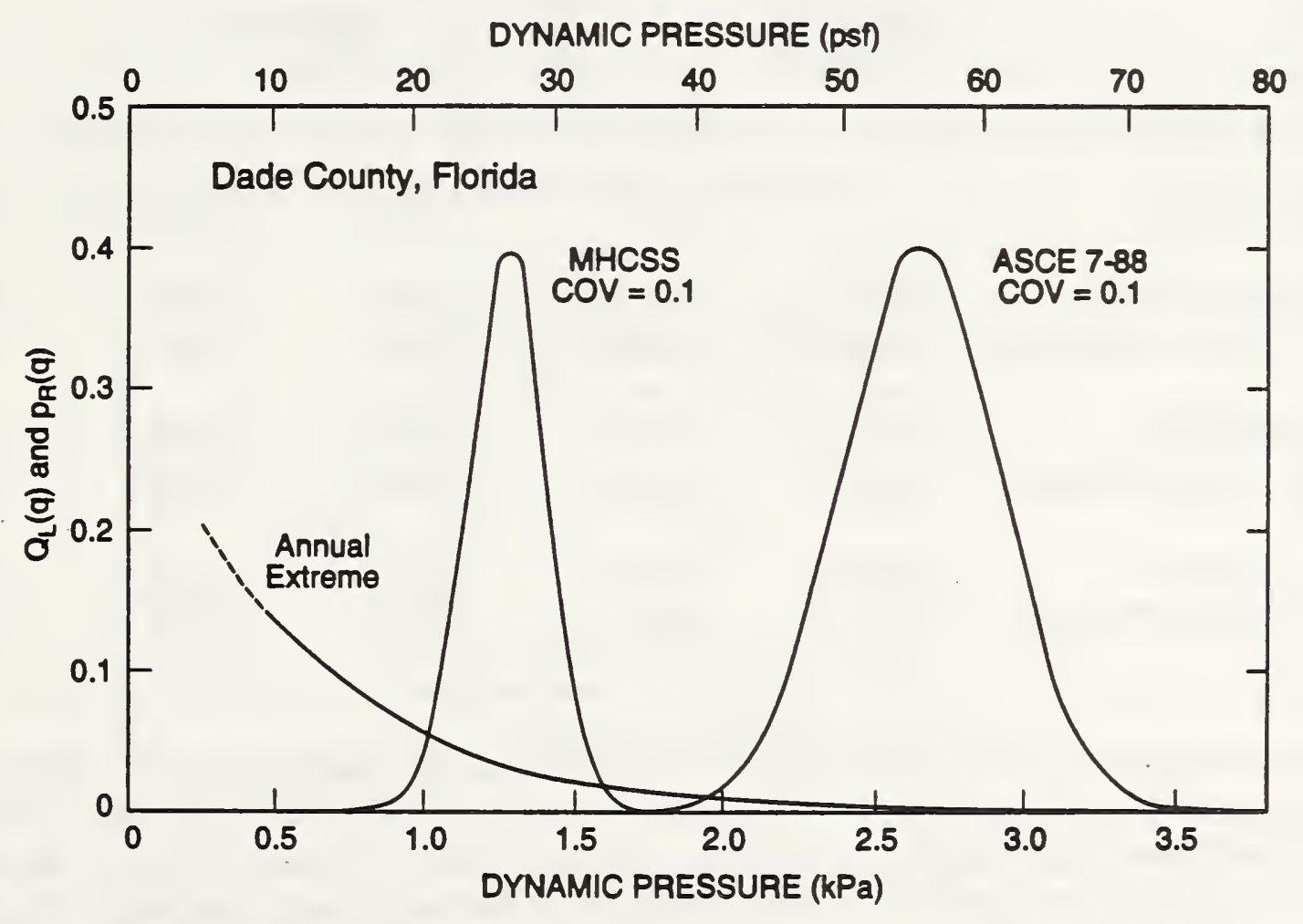

Figure 3. Probability functions for load and resistance, Dade County, Florida 
It can be seen from Table 1 that structures designed in accordance with the MHCSS wind load criteria and sited in Dade County, Florida, would have a risk of failure during a 10-yr exposure of the order of 10 times the risk for structures designed in accordance with the wind load provisions of ASCE 7-88. This same ratio is seen to apply for Omaha, Nebraska, even though the probabilities are about half those for Dade County. For Tucson, Arizona, the corresponding probability of failure during a 10-yr exposure is about 5 times that for structures designed in accordance with the ASCE 7-88 wind load criteria. Not shown in Table 1 are the effects of variability of resistance on the calculated probabilities. In general, increasing COV (R) will increase the probability of failure, particularly for lower mean values of resistance. For example, $P_{f(S o)}$ for Tucson, Arizona, ranges from 0.27 to 0.42 for a corresponding range in COV(R) of 0.05 to 0.20 in the case of the MHCSS wind load criteria.

The probabilities listed in Table 1 for Dade County, Florida, are based on the distributions of hurricane wind speeds developed by Georgiou et al. (1983). Other distributions will yield different values of $P_{f(\mathbb{N})}$. For example, using the distributions developed by Batts et al. (1980), $\mathrm{P}_{\mathrm{f}(5 .)}=0.790$ and 0.020 for the MHCSS and the ASCE 7-88 wind load criteria, respectively.

Table 1. Probability of Attaining Ultimate Limit State

$$
\phi=0.8 \quad \gamma_{\mathrm{w}}=1.3 \quad \operatorname{COV}(\mathrm{R})=0.1
$$

Location

Design

Probability

Criteria

Exposure Period

$1 \mathrm{yr}$

$10 \mathrm{yrs}$

$25 \mathrm{yrs}$

50 yrs

Dade County, Florida

MHCSS

0.036

0.310

0.605

0.844

$\mathrm{U}_{50}=49.2 \mathrm{~m} / \mathrm{s}(110 \mathrm{mph})$

ASCE 7

0.003

0.029

0.072

0.138

Omaha, Nebraska

MHCSS

0.018

0.165

0.362

0.594

$\mathrm{U}_{50}=37.1 \mathrm{~m} / \mathrm{s}(83 \mathrm{mph})$

ASCE 7

0.002

0.016

0.039

0.077

Tucson, Arizona

MHCSS

0.007

0.067

0.160

0.295

$\mathrm{U}_{50}=33.5 \mathrm{~m} / \mathrm{s}(75 \mathrm{mph})$

ASCE 7

0.001

0.014

0.034

0.066

The above comparisons are based on the assumptions that the dead load can be neglected and that the factored lift and drag loads are adequate indicators of structural resistance. For typical manufactured home construction, the factored roof dead load is a small fraction of the factored wind load. Although factored lift and drag forces may, for most design standards, be adequate indicators of strength, this assumption is not necessarily valid in the case of the MHCSS provisions that were in effect at the time of Hurricane Andrew. Specifically, there was no provision in the MHCSS for negative wind pressures acting on wall components and cladding. 


\subsection{FORCES ON ANCHORING SYSTEMS}

\subsection{General}

The forces to be resisted by anchoring systems depend upon the design wind speed or prescribed wind pressures, the size and geometry of the manufactured home superstructure, the manufactured home dead load, the live (occupancy) load, and the geometry of the anchoring system and supporting piers. Two sectional views of typical installation schemes are shown in Figure 4 along with the applied loads and reactions. Because the nea tie connection is by far the most common arrangement, the following discussion applies specifically to the upper diagram in Figure 4.

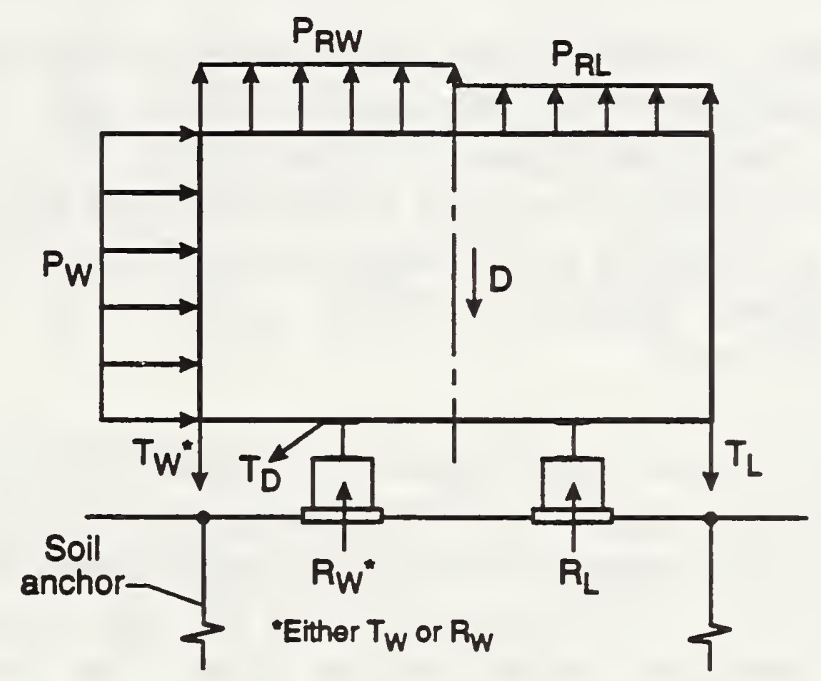

Near Tie Connection

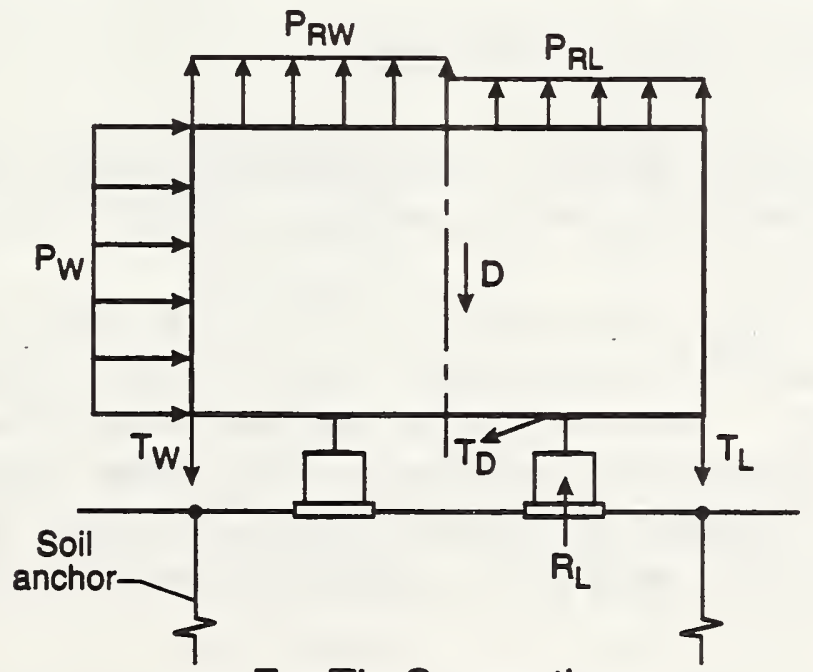

Far Tie Connection

Figure 4. Typical manufactured home installation schemes 
If it is assumed that the piers provide no resistance against sliding, then the entire horizontal (drag) load, $P_{W}$, must be resisted by the horizontal component of the diagonal tie force $T_{D}$. This assumption is reasonably consistent with the absence of any limitations on soil anchor displacement in ANSI A225.1-1987 which will be discussed subsequently. The windward vertical tie force, $T_{w}$, becomes active only if the windward pier force, $R_{w}$, is zero. Under this condition the effect of the wind loads is to promote overturning of the unit with the center of rotation located at the top of the leeward pier. Only when the uplift load, $\mathrm{P}_{\mathrm{RL}}$, acting on the leeward half of the roof surface becomes large relative to the combined dead and live load will the leeward tie forces become active.

\subsection{Nominal Loads}

For Zone I (standard zone), the MHCSS specifies a horizontal wind load of not less than 0.72 $\mathrm{kPa}(15 \mathrm{psf})$ and a net uplift load of not less than $0.43 \mathrm{kPa}(9 \mathrm{psf})$. These wind loads can be shown to correspond to a design wind speed of approximately $29.1 \mathrm{~m} / \mathrm{s}(65 \mathrm{mph})$. For Zone II (hurricane-resistive), the MHCSS wind load requirements that were in effect at the time of Hurricane Andrew were $1.20 \mathrm{kPa}(25 \mathrm{psf})$ horizontal and $0.72 \mathrm{kPa}(15 \mathrm{psf})$ net uplift, and these wind loads have been shown (Marshall 1993) to correspond to a design wind speed of approximately $35.8 \mathrm{~m} / \mathrm{s}$ (80 mph).

The nominal (code-specified) wind loads required by ASCE 7-88 for manufactured homes of typical size and geometry and located in Dade County, Florida, have been summarized by Marshall (1993). These loads are associated with a basic wind speed of $49.2 \mathrm{~m} / \mathrm{s}(110 \mathrm{mph})$ and a structure importance factor of 1.05 to account for the fact that the probability distribution of extreme speeds in hurricane-prone coastal regions differs from the distribution for inland regions. The corresponding drag and uplift loads for other wind speeds in non-hurricane regions can be obtained by multiplying the calculated loads for Dade County by the ratio

$$
[\mathrm{V} /(1.05 \times 110)]^{2}=\mathrm{V}^{2} / 13,340
$$

where $\mathrm{V}$ is the basic wind speed in mph. These nominal wind loads, along with the wind loads required by the MHCSS for Zones I and II, are listed in Table 2 for a range of wind speeds.

Manufactured home dead loads were studied by Yokel et al. (1981), and they recommended nominal values of 919 and $857 \mathrm{~Pa}$ (19.2 and $17.9 \mathrm{psf}$ ) for home widths of 3.658 and $4.267 \mathrm{~m}$ (12 and $14 \mathrm{ft}$ ), respectively. The corresponding dead-load eccentricities were determined to be 170 and $230 \mathrm{~mm}(0.55$ and $0.75 \mathrm{ft})$, respectively. Using these nominal dead loads and load eccentricities, Yokel et al. (1981) investigated the forces induced in the traditional tiedown schemes shown in Figure 4 by wind and by flood loads, and their format for presenting the results is used herein.

The trend in manufactured home construction is toward higher unit dead loads, and discussions with the technical staff of the Manufactured Housing and Construction Standards Division of HUD suggest a nominal value of $1.20 \mathrm{kPa}$ (25 psf) which includes the loads due to fixed 
equipment and major appliances.

Table 2. Nominal and Factored Wind Loads for Single- and Double-Wide Manufactured Honnes

Basic Wind Speed

Net Drag Load

Uplift

Windward Roof

$(\mathrm{m} / \mathrm{s}) \quad(\mathrm{mph})$

(kPa) (psf)

(kPa) (psf)

Uplift

Leeward Roof

(kPa) (psf)

\section{MHCSS}

Nominal Loads:

Zone I

Zone II
0.72

1.20

(15)

(25)

0.43

0.72

(9)

(15)

0.43

0.72

Factored Loads:

Zone I
Zone II

$1.08(22.5)$

1.80 (37.5)
0.65 (13.5)

1.08 (22.5)
0.65 (13.5)

1.08 (22.5)

\section{ASCE 7-88}

Nominal Loads:
$31.3 \quad(70)$
0.82 (17.2)
0.57 (11.9)
$0.45 \quad(9.3)$
$35.8 \quad(80)$
$1.08(22.5)$
0.75 (15.6)
$0.58(12.1)$
$40.2 \quad(90)$
$1.36(28.5)$
0.94 (19.7)
0.73 (15.3)
$44.7 \quad(100)$
1.69 (35.2)
1.17 (24.4)
$0.90(18.9)$

Factored Loads:

$\begin{array}{rrrrrrr}31.3 & (70) & 1.07(22.4) & 0.74(15.5) & 0.58(12.1) \\ 35.8 & (80) & 1.40(29.3) & 0.97(20.3) & 0.75(15.7) \\ 40.2 & (90) & 1.77(37.0) & 1.23(25.6) & 0.95(19.9) \\ 44.7 & (100) & 2.19(45.8) & 1.52(31.7) & 1.18(24.6)\end{array}$




\subsection{Factored Loads}

For the design of anchoring systems the MHCSS requires that such systems be capable of resisting without failure the wind forces of either Zone I or Zone II, increased by 50 percent. The MHCSS goes on to require that the basic allowable stresses for materials used to resist overturning and lateral movement shall not be increased in the design and proportioning of these members or system components. The MHCSS does not permit the inclusion of floor live loads when calculating the resistance to overturning by wind forces. Taken at face value, these requirements introduce some confusion in that the first requirement is consistent with an LRFD format while the use of allowable stresses implies an ASD format. In terms of factored loads the MHCSS requirement for windstorm protection has the form

$$
\mathrm{F}=\mathrm{D}+1.5 \mathrm{~W}
$$

As was noted earlier, ASCE 7-88 specifies certain load combinations for LRFD. These combinations include

and

$$
F=1.2 \mathrm{D}+1.3 \mathrm{~W}+0.5 \mathrm{~L}
$$

$$
F=0.9 D+1.3 W
$$

where $\mathrm{D}, \mathrm{W}$ and $\mathrm{L}$ are the nominal dead load, wind load and floor live load, respectively. The factored wind loads (1.5W for MHCSS and 1.3W for ASCE 7-88) are listed along with the nominal wind loads in Table 2.

The first load combination listed for ASCE 7-88 is intended for those situations where the critical load effects are additive and have the same sign as, for example, in the case of a leeward column. Consequently, this load combination is not applicable to the design of manufactured home anchoring systems. The second load combination was used previously in estimating probabilities of failure of manufactured home superstructures (boxes) under the action of counteracting loads. For determining resistance to sliding and overturning the relevant loads are again counteracting, and the dead load now becomes a significant load component. Data from which to estimate a COV for the dead load eccentricities are not available, and the following analysis of tie and pier forces using factored loads is based on the load combination $F=0.9 \mathrm{D}$ $+1.3 \mathrm{~W}$ with $\mathrm{D}=1.20 \mathrm{kPa}$ ( $25 \mathrm{psf}$ ) and the assumption that the dead load eccentricity is zero.

To illustrate the difference in nominal and factored loads, the corresponding tie and pier forces per unit length of home are listed in Table 3. A typical loading diagram and the associated calculations for the factored tie and pier forces corresponding to Zone I in the case of the MHCSS and to a basic wind speed of $40.2 \mathrm{~m} / \mathrm{s}(90 \mathrm{mph})$ and a category C exposure in the case of ASCE 7-88 are given in the Appendix. The analysis is based on the following assumptions: 
Width of home $=4.267 \mathrm{~m}(14 \mathrm{ft})$

Net box height $=2.438 \mathrm{~m}(8 \mathrm{ft})$

Center-to-center pier or main-frame spacing $=2.134 \mathrm{~m}(7 \mathrm{ft})$

Angle of diagonal tie $=45$ degrees

Nominal dead load $=1.20 \mathrm{kPa}(25 \mathrm{psf})$ acting through geometric center of home

The piers provide no lateral resistance

Again, it should be emphasized that for the design of support and anchoring systems, the MHCSS requires the combination of the factored wind loads and the nominal dead load with no increase in the basic allowable stresses. For the case of the ASCE 7-88 load combinations, nominal loads are to be used in conjunction with ASD while the factored loads and appropriate materials resistance factors are to be used in conjunction with LRFD. Note that since the windward diagonal tie force, $T_{D}$, depends only upon the drag load and the tie angle, the resulting values of $T_{D}$ apply to both single- and double-wide manufactured homes. To establish the approximate range of diagonal tie and pier loads that might be encountered, the ASCE 7-88 requirements are listed in Table 3 for basic wind speeds ranging from 31.3 to $44.7 \mathrm{~m} / \mathrm{s}$ (70 to $100 \mathrm{mph})$.

The effect of the main-frame spacing (center-to-center distance between main longitudinal members) on the diagonal tie and pier loads is shown in Table 4. For a given width of home, the load on the windward pier increases with increasing frame spacing while the load on the leeward pier decreases. 
Table 3. Loads per Unit Length of Home Acting on Diagonal Ties and Piers for Typical SingleWide Manufactured Home

Basic Wind Speed Tie Angle $(\mathrm{m} / \mathrm{s}) \quad(\mathrm{mph}) \quad$ (degrees)
$T_{D}$ $(\mathrm{kN} / \mathrm{m})(\mathrm{lbf} / \mathrm{ft}) \quad(\mathrm{kN} / \mathrm{m})(\mathrm{lbf} / \mathrm{ft}) \quad(\mathrm{kN} / \mathrm{m})(\mathrm{lbf} / \mathrm{ft})$

\section{MHCSS}

Nominal Loads:

$\begin{array}{llllllll}\text { Zone I } & 45 & 2.48 & (170) & 2.38 & (163) & 2.64 & (181) \\ \text { Zone II } & 45 & 4.13 & (283) & 2.27 & (156) & 2.69 & (184)\end{array}$

Factored Loads:

\section{Zone I \\ Zone II}

45

45
$3.71 \quad$ (255)

$6.19 \quad$ (424)
2.30

2.13
(158)

(146)
2.68

2.76

\section{ASCE 7-88}

Nominal Loads:

$\begin{array}{lrlllllll}31.3 & (70) & 45 & 2.84 & (195) & 2.20 & (151) & 2.75 & (189) \\ 35.8 & (80) & 45 & 3.71 & (255) & 2.09 & (143) & 2.82 & (193) \\ 40.2 & (90) & 45 & 4.71 & (322) & 1.97 & (135) & 2.89 & (198) \\ 44.7 & (100) & 45 & 5.81 & (398) & 1.82 & (125) & 2.97 & (204)\end{array}$

Factored Loads:

$\begin{array}{rrrrrrrrr}31.3 & (70) & 45 & 3.69 & (253) & 1.84 & (126) & 2.56 & (175) \\ 35.8 & (80) & 45 & 4.83 & (331) & 1.69 & (116) & 2.64 & (181) \\ 40.2 & (90) & 45 & 6.12 & (419) & 1.54 & (105) & 2.74 & (188) \\ 44.7 & (100) & 45 & 7.55 & (518) & 1.35 & (92) & 2.84 & (195)\end{array}$

Notes:

$$
\begin{aligned}
& T_{D}=\text { Windward diagonal tie force } \\
& R_{W}=\text { Windward pier reaction } \\
& R_{L}=\text { Leeward pier reaction }
\end{aligned}
$$


Table 4. Effect of Main-Frame Spacing on Diagonal Tie and Pier Loads for Single-Wide and Double-Wide Manufactured Homes. Basic wind speed $=40.2 \mathrm{~m} / \mathrm{s}(90 \mathrm{mph})$.

\section{Frame Spacing $\quad T_{D} \quad R_{W} \quad R_{L}$

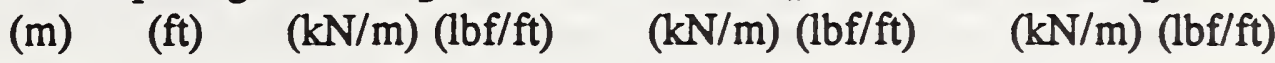

Single-Wide Unit

Nominal Loads:

$\begin{array}{rrrrrrrr}1.829 & (6) & 4.71 & (322) & 1.61 & (111) & 3.25 & (222) \\ 2.134 & (7) & 4.71 & (322) & 1.97 & (135) & 2.89 & (198) \\ 2.438 & (8) & 4.71 & (322) & 2.23 & (153) & 2.63 & (180) \\ 4.267 & (14) & 4.71 & (322) & 3.03 & (208) & 1.83 & (125) \\ & & & & & & & \\ 1.829 & (6) & 6.12 & (419) & 1.08 & (74) & 3.20 & (219) \\ 2.134 & (7) & 6.12 & (419) & 1.54 & (105) & 2.74 & (188) \\ 2.438 & (8) & 6.12 & (419) & 1.88 & (129) & 2.39 & (164) \\ 4.267 & (14) & 6.12 & (419) & 2.92 & (200) & 1.36 & (93)\end{array}$

Double-Wide Unit Nominal Loads:

$\begin{array}{llllllll}5.486 & (18) & 4.71 & (322) & 3.77 & (258) & 2.62 & (180) \\ 6.096 & (20) & 4.71 & (322) & 3.88 & (266) & 2.51 & (172) \\ 6.401 & (21) & 4.71 & (322) & 3.93 & (269) & 2.47 & (169) \\ 6.706 & (22) & 4.71 & (322) & 3.97 & (272) & 2.42 & (166) \\ 8.535 & (28) & 4.71 & (322) & 4.16 & (285) & 2.23 & (153) \\ & & & & & & & \\ 5.486 & (18) & 6.12 & (419) & 2.86 & (196) & 1.36 & (94) \\ 6.096 & (20) & 6.12 & (419) & 3.00 & (206) & 1.22 & (84) \\ 6.401 & (21) & 6.12 & (419) & 3.06 & (210) & 1.16 & (80) \\ 6.706 & (22) & 6.12 & (419) & 3.12 & (214) & 1.11 & (76) \\ 8.535 & (28) & 6.12 & (419) & 3.36 & (231) & 0.86 & (59)\end{array}$

Notes:

$T_{D}=$ Windward diagonal tie force

$\mathbf{R}_{\mathrm{W}}=$ Windward pier reaction

$\mathbf{R}_{\mathrm{L}}=$ Leeward pier reaction

Loads are per unit length of home

Loads are based on ASCE 7-88 with basic wind speed $=40.2 \mathrm{~m} / \mathrm{s}(90 \mathrm{mph})$ and a diagonal tie angle of 45 degrees.

Width: $\quad$ Single-wide $=4.267 \mathrm{~m}(14 \mathrm{ft})$

Double-wide $=8.535 \mathrm{~m}(28 \mathrm{ft})$ 
In Figure 5 are plotted the tie and pier forces per unit length of home for a range of angles that the diagonal tie makes with the horizontal. The home is a single-wide unit as described in the Appendix, and the applied wind loads are the MHCSS Zone I values multiplied by a factor of 1.5. An inspection of Figure 5 reveals the following:

- There is a critical diagonal tie angle (approximately 7 degrees in this case) where the windward pier load becomes zero, and this angle defines the boundary between the manufactured home overturning regime and sliding regime.

- For diagonal tie angles greater than about 7 degrees, there is no force in the windward vertical tie.

- The windward diagonal tie forces and windward pier forces are closely related and increase rapidly for tie angles greater than about 50 degrees.

- For a given main-frame spacing, the leeward pier force is independent of the diagonal tie angle in the sliding regime.

- There are no forces in the leeward ties.

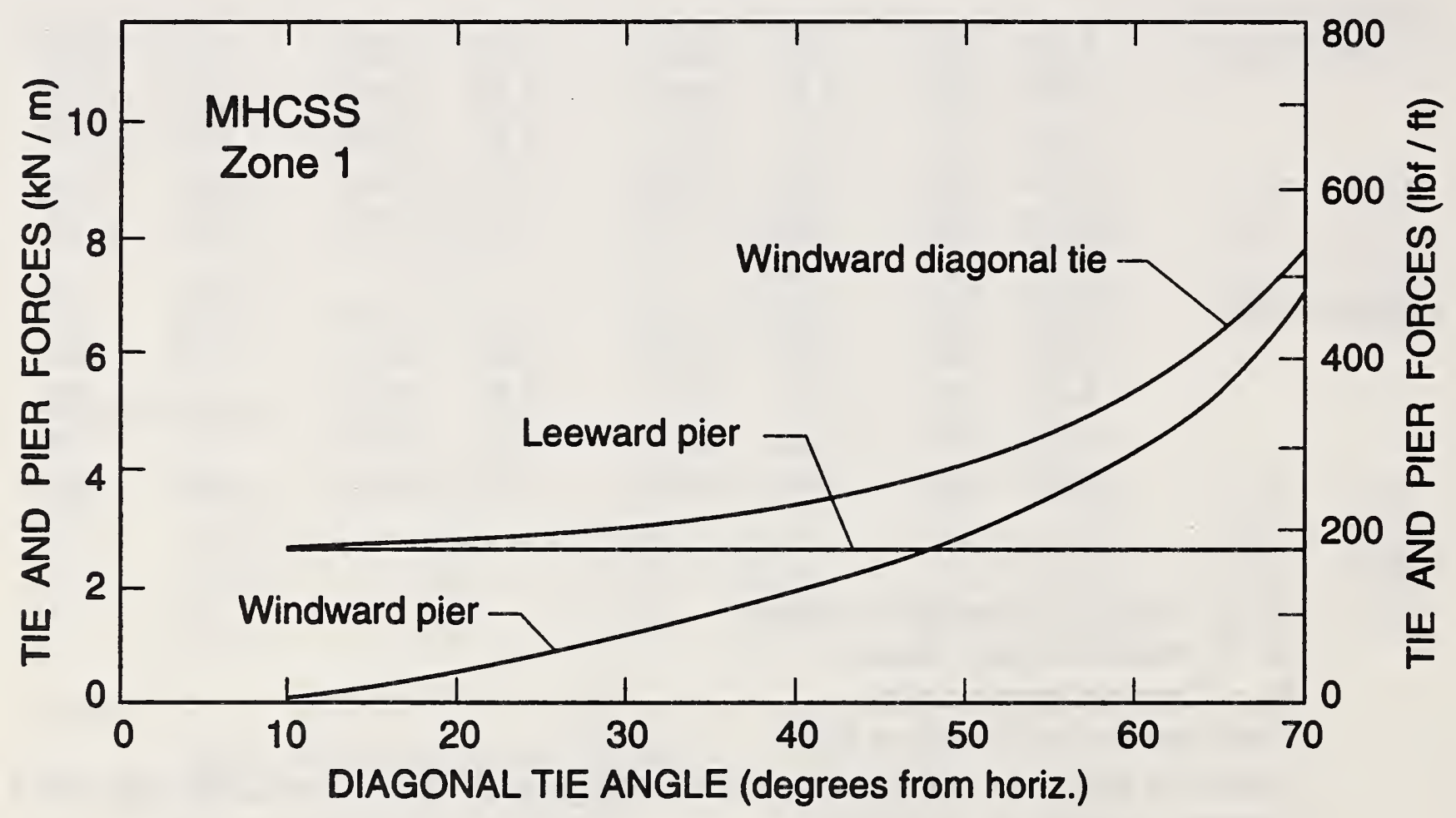

Figure 5. Tie and pier forces per unit length for a single-wide home and MHCSS Zone I factored wind loads. (See Appendix for typical force calculations) 
Figure 6 shows the results of a similar factored load analysis for a single-wide manufactured home with the wind loads corresponding to the requirements of ASCE 7-88 and a basic wind speed of $40.2 \mathrm{~m} / \mathrm{s}(90 \mathrm{mph})$ in exposure category C. The trends are similar to those of Figure 5 , but now the angle of demarcation between the manufactured home overturning and sliding regimes is increased to about 33 degrees. Based on the results shown in Figures 5 and 6, it is apparent that

- The ANSI A225.1 requirement that the angle of the diagonal frame ties not deviate more than \pm 5 degrees from 45 degrees has considerable merit since the diagonal tie load increases rapidly at larger angles, and the overturning regime is encountered at smaller angles.

- If the diagonal ties and associated anchors are properly designed and installed, there are no obvious benefits to be derived from vertical ties in resisting wind forces. Note, however, that vertical ties may be effective in resisting buoyancy forces associated with flooding.

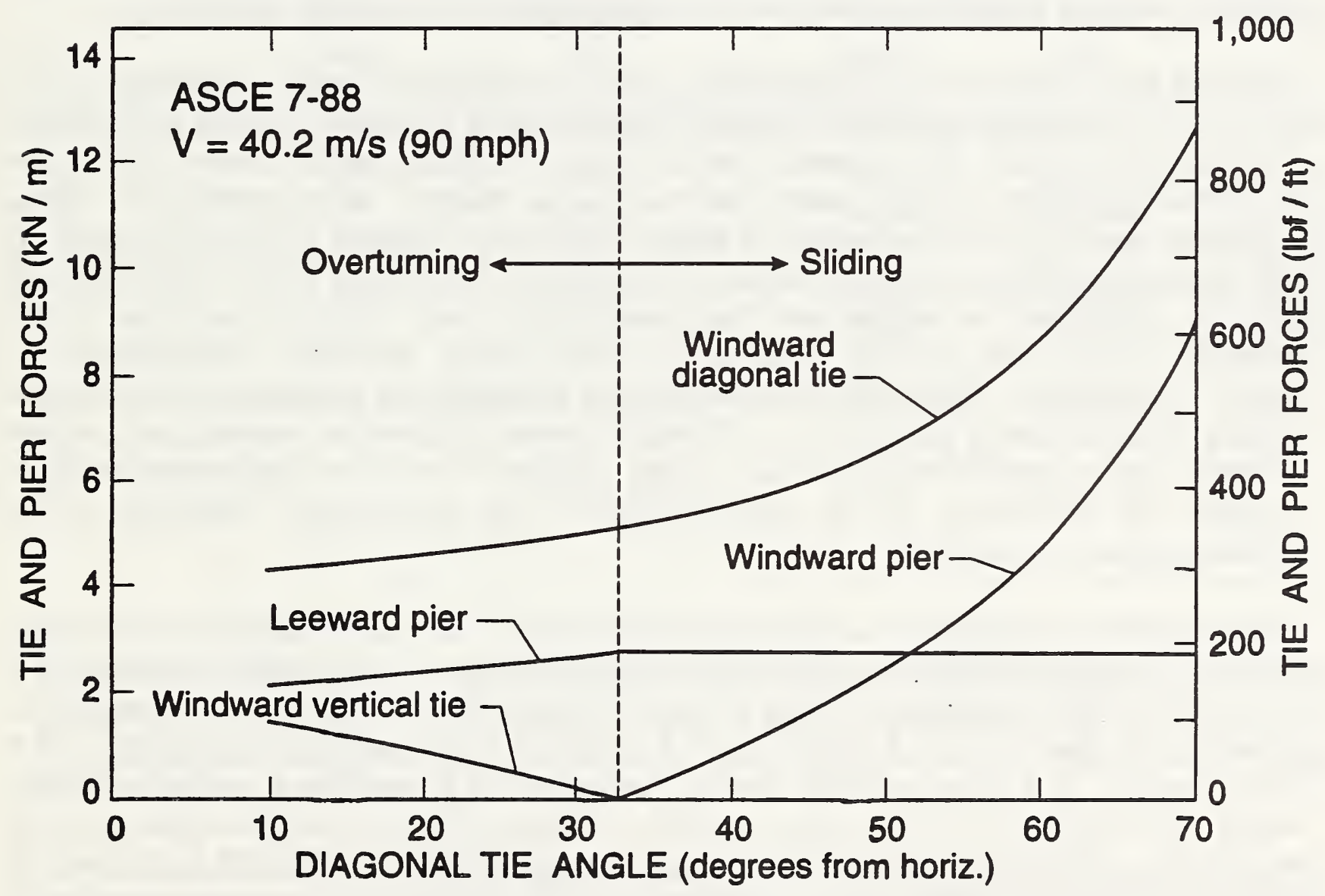

Figure 6. Tie and pier forces per unit length for a single-wide home and factored loads with ASCE 7-88 basic wind speed of $40.2 \mathrm{~m} / \mathrm{s}$ ( $90 \mathrm{mph}$ ). (See Appendix for typical force calculations) 


\subsection{LOAD CAPACITY OF ANCHORING SYSTEMS}

\subsection{Background}

Included in the MHCSS provisions for windstorm protection is the requirement for an allowable working load of $14.01 \mathrm{kN}(3,150 \mathrm{lbf})$ for anchoring components and a 50 percent overload $(21.02 \mathrm{kN}(4,725 \mathrm{lbf}))$ without failure of either the anchoring equipment or the attachment point on the manufactured home. These load requirements are consistent with those of Sec. 3-2.9.1 of ANSI A225.1-1982 (Manufactured Home Installations) where failure is further defined to include limitations on soil anchor displacement. Specifically, failure is considered to have occurred when the point of connection between the tie and soil anchor (anchor head) moves more than $51 \mathrm{~mm}(2 \mathrm{in}$.) at a load of $21.02 \mathrm{kN}(4,725 \mathrm{lbf})$ in the direction of the vertical tie. For those soil anchors that are designed to be installed so that the loads act in directions other than direct withdrawal, the horizontal displacement of the anchor head is not to exceed $102 \mathrm{~mm}$ (4 in.) when the working load is applied at 45 degrees from the horizontal. Sec. 3-2.9.1 further states that "Anchors designed for connection of multiple ties shall be capable of resisting the combined working load and overload consistent with the intent expressed herein."

Given that the allowable vertical displacement is associated with the overload condition of 21.02 $\mathrm{kN}(4,725 \mathrm{lbf})$ while the allowable horizontal displacement is associated with the working load of $14.01 \mathrm{kN}(3,150 \mathrm{lbf})$, the "...intent expressed herein" is open to various interpretations when the anchoring scheme involves more than one tie per anchor, not to mention the added uncertainty when tie forces are applied at angles other than 45 degrees with the horizontal. It is of interest to note that the current version of ANSI A225.1 (NCSBCS A225.1-1987) does not place any restrictions on anchor-head displacement under load, although the values of the allowable working load and the 50 percent overload remain unchanged. Presumably, the original limitations on horizontal displacement were developed out of concern for the lateral stability of the supporting piers which, traditionally, consist of unbonded, unreinforced concrete masonry units or prefabricated steel jack stands. Neither of the above-referenced standards provides any commentary on the original intent of the displacement limitations or the justification for their deletion.

Regardless of any limitations on anchor head displacement, ANSI A225.1 specifies the minimum number of anchors and ties for a given length of manufactured home located in either Zone I or Zone II. When diagonal ties alone are used to resist wind forces, the corresponding tie spacing ranges from 3.9 to $5.5 \mathrm{~m} \mathrm{(12.8} \mathrm{to} 18 \mathrm{ft}$ ) for Zone I and from 2.0 to $2.6 \mathrm{~m} \mathrm{(6.6} \mathrm{to} 8.5$ $\mathrm{ft}$ ) for Zone II. It is stated explicitly that the number of ties is based on a minimum working load of $14.01 \mathrm{kN}(3,150 \mathrm{lbf})$ per anchor, and this working load and the implied anchor spacings are consistent with the design wind loads that were specified in the MHCSS at the time of Hurricane Andrew. Implicit in the requirements of ANSI A225.1 is the assumption that it will always be possible to provide a safe working load of $14.01 \mathrm{kN}(3,150 \mathrm{lb})$ per anchor, regardless of the actual soil conditions. As will be demonstrated shortly, this assumption appears to be overly optimistic. 


\subsection{Steel Strapping}

Results of laboratory tests carried out by Pearson et al. (1991) on cold-rolled steel strapping obtained from five suppliers are summarized in Table 5. The tests were conducted in accordance with ASTM D3953-83 (Standard Specification for Flat Steel Strap and Connectors), and the nominal cross-sectional dimensions of the specimens were $31.75 \times 0.89 \mathrm{~mm}(1-1 / 4 \mathrm{x}$ 0.035 in.). It is seen from Table 5 that three of the five products tested did not meet the ASTM minimum requirements for elongation or ultimate strength, the worst case being an average ultimate strength of $18.09 \mathrm{kN}(4,068 \mathrm{lbf})$ or 86 percent of the MHCSS requirement. The average ultimate strengths and their standard deviations are compared with the requirement of ANSI A225.1 in Figure 7.

Table 5. Results of Laboratory Tension Tests on Cold-Rolled Steel Strapping (Pearson et al. 1991)

\begin{tabular}{cccccc}
\hline Product & $\begin{array}{c}\text { No. of } \\
\text { Tests }\end{array}$ & $\begin{array}{c}\text { Elongation } \\
(\%)\end{array}$ & $\begin{array}{l}\text { Average Max. Load } \\
(\mathrm{kN})\end{array}$ & COV \\
$(\mathrm{lbf})$ & \\
\hline & 3 & 8.0 & 25.04 & $(5,630)$ & 0.015 \\
2 & 4 & 4.6 & 18.09 & $(4,068)$ & 0.006 \\
3 & 4 & 9.3 & 25.39 & $(5,708)$ & 0.009 \\
4 & 5 & 5.4 & 19.21 & $(4,318)$ & 0.003 \\
5 & 3 & 3.2 & 20.31 & $(4,567)$ & 0.026 \\
Based on mean ultimate strengths of 5 products & 21.61 & $(4,858)$ & 0.157 \\
\multicolumn{7}{l}{ ASTM D3953-83 } & 6.5 (Min) & 21.13 & $(4,750)$ & \\
\end{tabular}

Not listed in Table 5 are the results of bending tests (number of bends before breaking). While all specimens passed this test, the average number of bends prior to failure for the two products with the highest elongation was approximately three times greater than the number of bends exhibited by the other products.

Vann and McDonald (1978) present data to indicate that the actual breaking strength of installed strapping may be only 80 percent of the strength indicated by ASTM D3953 due to the flexing involved with strap installation, imperfect wrapping of the strapping around tensioning devices, and stress concentrations caused by buckles and similar hardware used to secure strapping. 


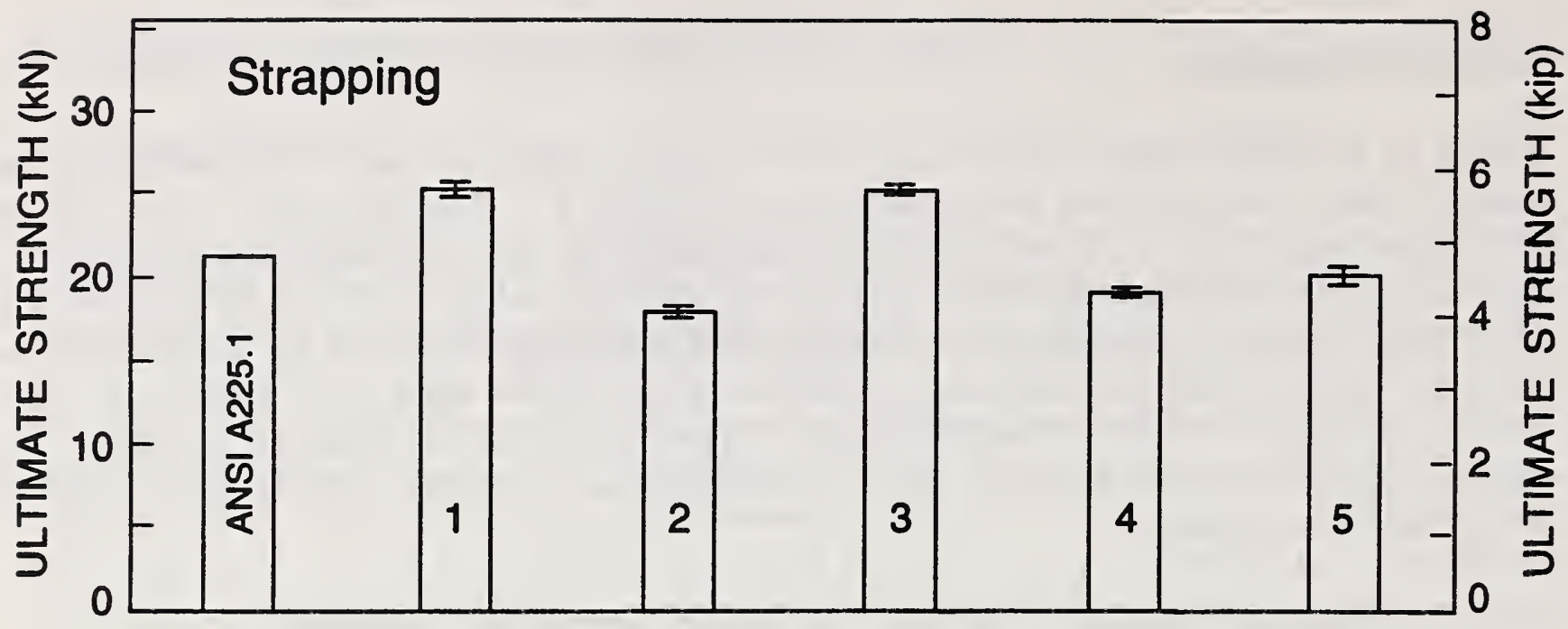

Figure 7. Results of laboratory tension tests on cold-rolled steel strapping (Pearson et al. 1991)

Considering the test data presented herein, it appears that the anchor system requirements of the MHCSS and of ANSI A225.1 are based almost entirely on the nominal breaking strength of $31.75 \times 0.89 \mathrm{~mm}(1-1 / 4 \times 0.035$ in.) cold-rolled strapping with a $1 / 3$ reduction for allowable working load. There appears to have been no recognition of the variability of ultimate strength from product-to-product or the adverse effects of strap installation on ultimate strength. While the variability of ultimate strength for a given product is small (COV typically less than 0.02), the variation between products and the detrimental effects of installation need to be accounted for. Unfortunately, test data on the strength of installed strapping are insufficient to quantify the variability, but the limited data that are available suggest a reduction factor of approximately 0.80 and a corresponding in-service ultimate strength no greater than $16.90 \mathrm{kN}(3,800 \mathrm{lbf})$.

\subsection{Mechanical Strength of Soil Anchors}

In a series of axial load tests carried out on soil anchors obtained from 9 manufacturers, Pearson et al. (1991) identified several modes of failure and obtained sufficient test data from which to quantify the variability of ultimate strength. The tests were carried out in a loading frame with the anchor helix plate(s) embedded in a sand-filled box or square tube designed to preclude any failure of the confining soil. Physical dimensions of the 9 products tested are listed in Table 6 and the test results are summarized in Table 7. Ultimate strengths and their standard deviations are plotted in Figure 8. In order of frequency of occurrence, the following failure modes were observed:

U-Connection/Rod Weld Failure
U-Connection Failure
Disk Failure
Disk/Rod Weld Failure

42 percent

Ten of the test specimens experienced more than one mode of failure. 
Table 6. Dimensions of Soil Anchors Tested by Pearson et al. (1991)

\begin{tabular}{|c|c|c|c|c|c|c|c|}
\hline \multirow{2}{*}{$\begin{array}{c}\text { Anchor } \\
\text { Manufacturer } \\
1\end{array}$} & \multicolumn{2}{|c|}{$\begin{array}{l}\text { Shaft Diameter } \\
(\mathrm{mm}) \quad \text { (in.) }\end{array}$} & \multicolumn{2}{|c|}{$\begin{array}{l}\text { Shaft Length } \\
\begin{array}{ll}(\mathrm{mm}) & \text { (in.) }\end{array}\end{array}$} & \multicolumn{2}{|c|}{$\begin{array}{l}\text { Disk Diameter } \\
(\mathrm{mm}) \quad \text { (in.) }\end{array}$} & $\begin{array}{l}\text { Number of } \\
\text { Disks }\end{array}$ \\
\hline & 15.9 & $(5 / 8)$ & 762 & (30) & 102 & (4) & 2 \\
\hline 2 & 15.9 & $(5 / 8)$ & 1,219 & $(48)$ & 152 & (6) & 1 \\
\hline 3 & 19.1 & $(3 / 4)$ & 1,219 & (48) & 102 & (4) & 2 \\
\hline 4 & 17.5 & $(11 / 16)$ & 1,219 & $(48)$ & 152 & (6) & 1 \\
\hline 5 & 15.9 & $(5 / 8)$ & 1,219 & (48) & 152 & (6) & 1 \\
\hline 6 & 15.9 & $(5 / 8)$ & 1,219 & (48) & 152 & (6) & 1 \\
\hline 7 & 17.5 & $(11 / 16)$ & 914 & $(36)$ & 152 & (6) & 1 \\
\hline 8 & 15.9 & $(5 / 8)$ & 1,219 & (48) & .127 & (5) & 1 \\
\hline 9 & 15.9 & $(5 / 8)$ & 1,219 & (48) & 152 & (6) & 1 \\
\hline
\end{tabular}

Table 7. Mechanical Strength of Axially Loaded Soil Anchors (Pearson et al. 1991)

\begin{tabular}{|c|c|c|c|c|}
\hline $\begin{array}{c}\text { Anchor } \\
\text { Manufacturer }\end{array}$ & $\begin{array}{l}\text { No. of } \\
\text { Tests }\end{array}$ & $\begin{array}{l}\text { Average } \\
(\mathrm{kN})\end{array}$ & $\begin{array}{l}\text { Maximum Load } \\
\text { (lbf) }\end{array}$ & $\mathrm{COV}$ \\
\hline 1 & 4 & 50.49 & $(11,352)$ & 0.12 \\
\hline 2 & 5 & 30.27 & $(6,806)$ & 0.06 \\
\hline 3 & 5 & 51.25 & $(11,523)$ & 0.04 \\
\hline 4 & 5 & 77.71 & $(17,471)$ & 0.08 \\
\hline 5 & 4 & 38.72 & $(8,704)$ & 0.19 \\
\hline 6 & 5 & 30.66 & $(6,892)$ & 0.07 \\
\hline 7 & 5 & 33.48 & $(7,526)$ & 0.12 \\
\hline 8 & 5 & 24.34 & $(5,471)$ & 0.24 \\
\hline 9 & 5 & 36.92 & $(8,301)$ & 0.10 \\
\hline Products 4 \& 8 excluded & 33 & 38.48 & $(8,650)$ & 0.23 \\
\hline
\end{tabular}


It is seen from Table 7 that the average mechanical strength of each of the 9 products tested exceeds the MHCSS overload requirement of $21.02 \mathrm{kN}(4,725 \mathrm{lbf})$, in certain instances by a substantial margin. However, because of its large coefficient of variation, product \#8 does not satisfy either the working load or overload requirement of the MHCSS. If the products with the highest and the lowest average maximum capacities are excluded, the statistics of the combined load tests are characterized by a mean ultimate strength of $38.48 \mathrm{kN}(8,650 \mathrm{lbf})$ and $\mathrm{COV}=$ 0.23. Even with this large variation, the ultimate mechanical strength of the anchors is well above the reduced strap capacity of $16.90 \mathrm{kN}(3,800 \mathrm{lbf})$. However, these test results for anchors probably over-estimate their in-service mechanical strength because of damage induced during their installation. The appropriate strength reduction factor to account for this damage is not known.

\section{Anchors}

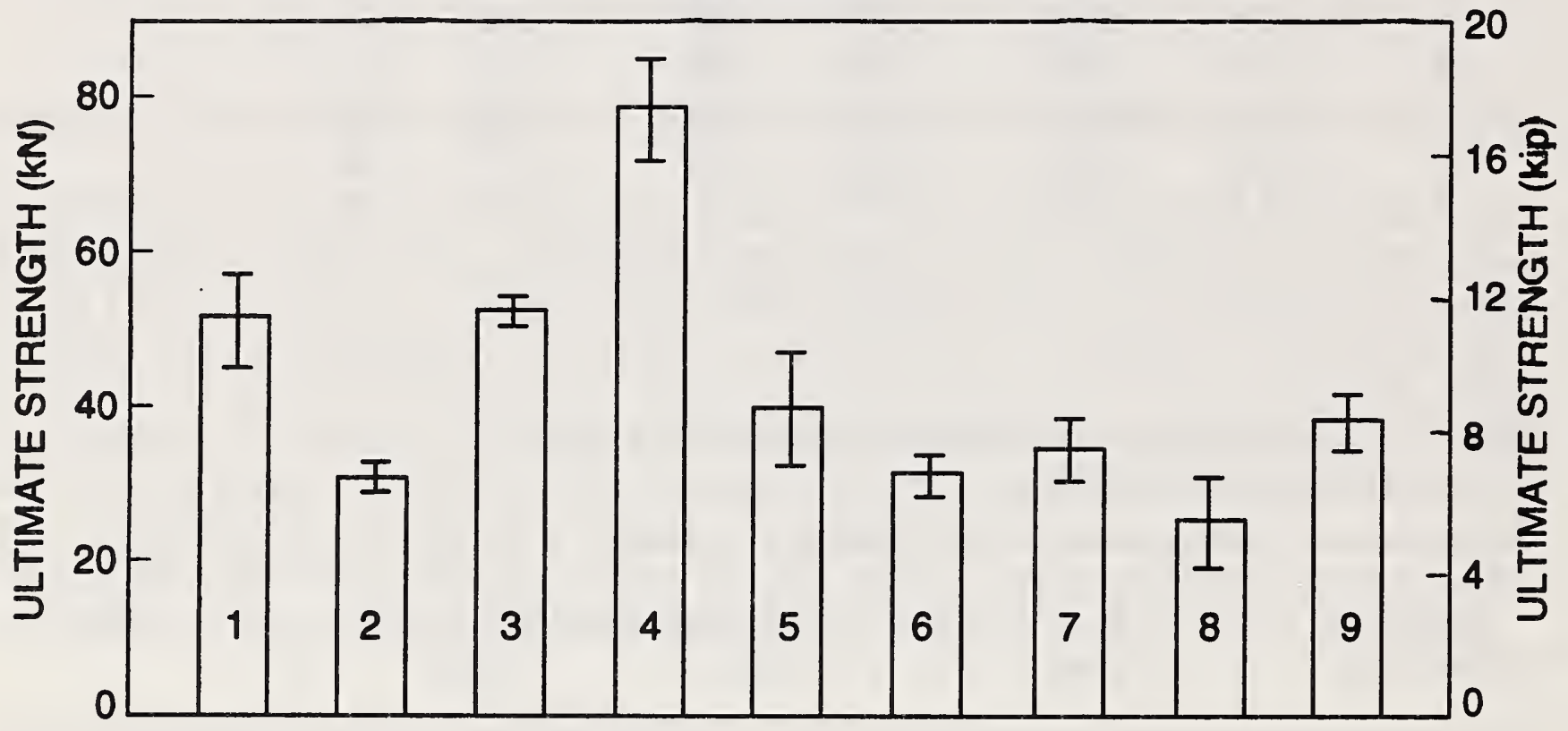

Figure 8. Mechanical strength of axially loaded soil anchors (Pearson et al. 1991)

\subsection{Pull-Out Capacity of Soil Anchors}

Subsequent to the laboratory load tests described above, Pearson et al. (1991) conducted a series of field pull-out tests on fully-embedded soil anchors at a test site characterized as "loose to medium dense" sand. In this test series and in other pull-out tests to be discussed later, reference is made to Figure 9 which defines the anchor orientation and angle of load application. Limiting displacement criteria per ANSI A225.1 and typical anchor deformation under inclined loading are indicated in Figure 10. 


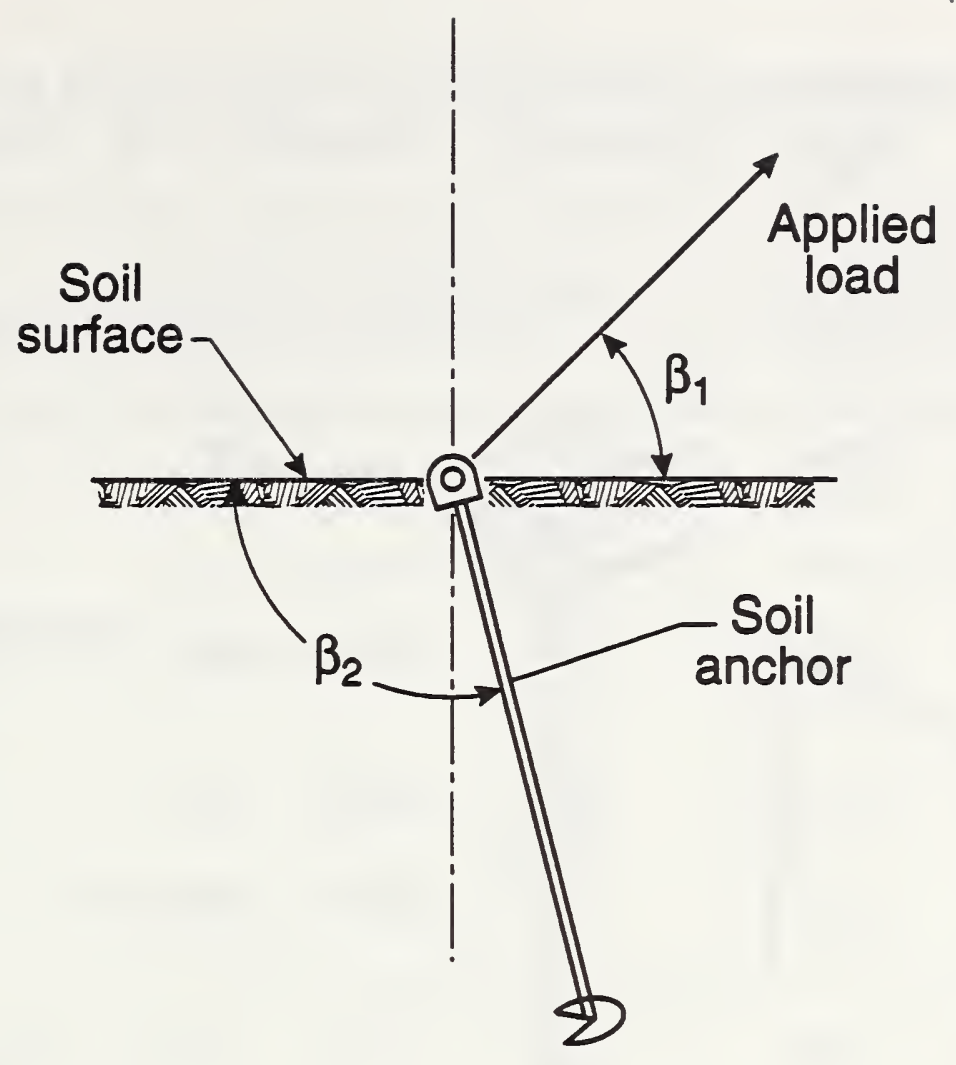

Figure 9. Definition sketch showing soil anchor orientation and angle of load application

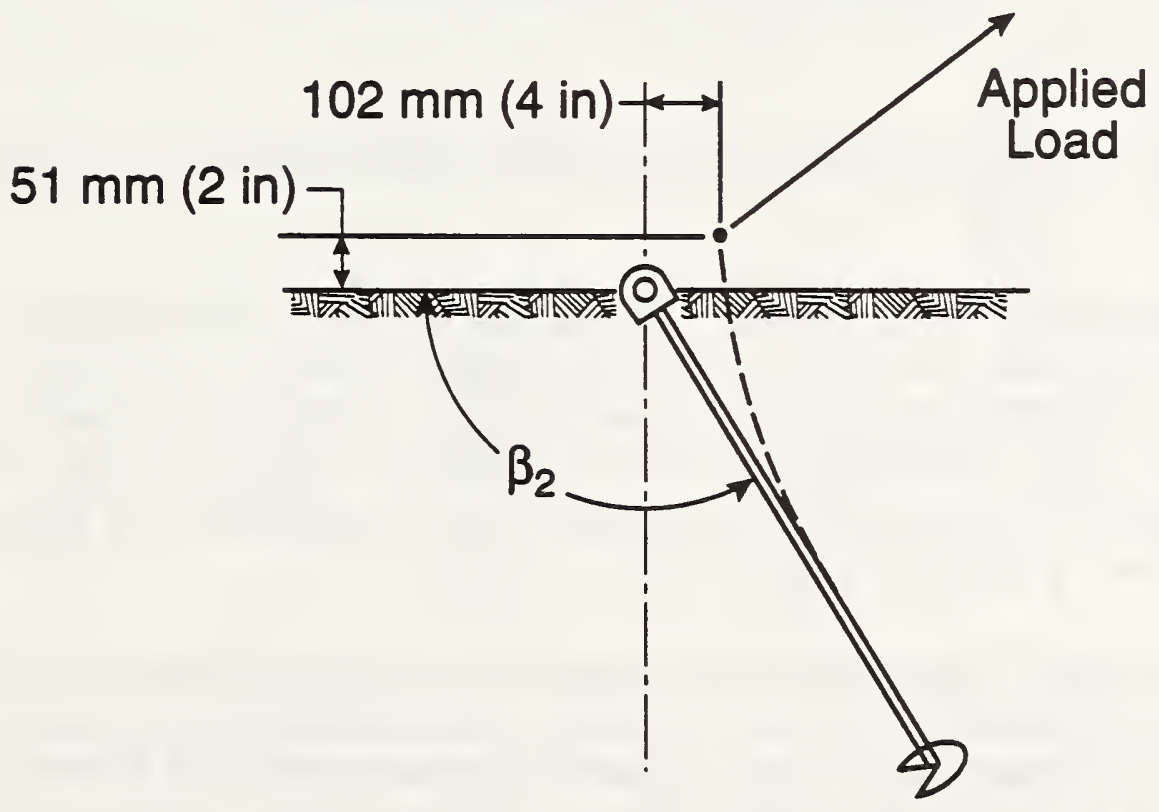

Figure 10. Limiting displacements and shape of deformed soil anchor 


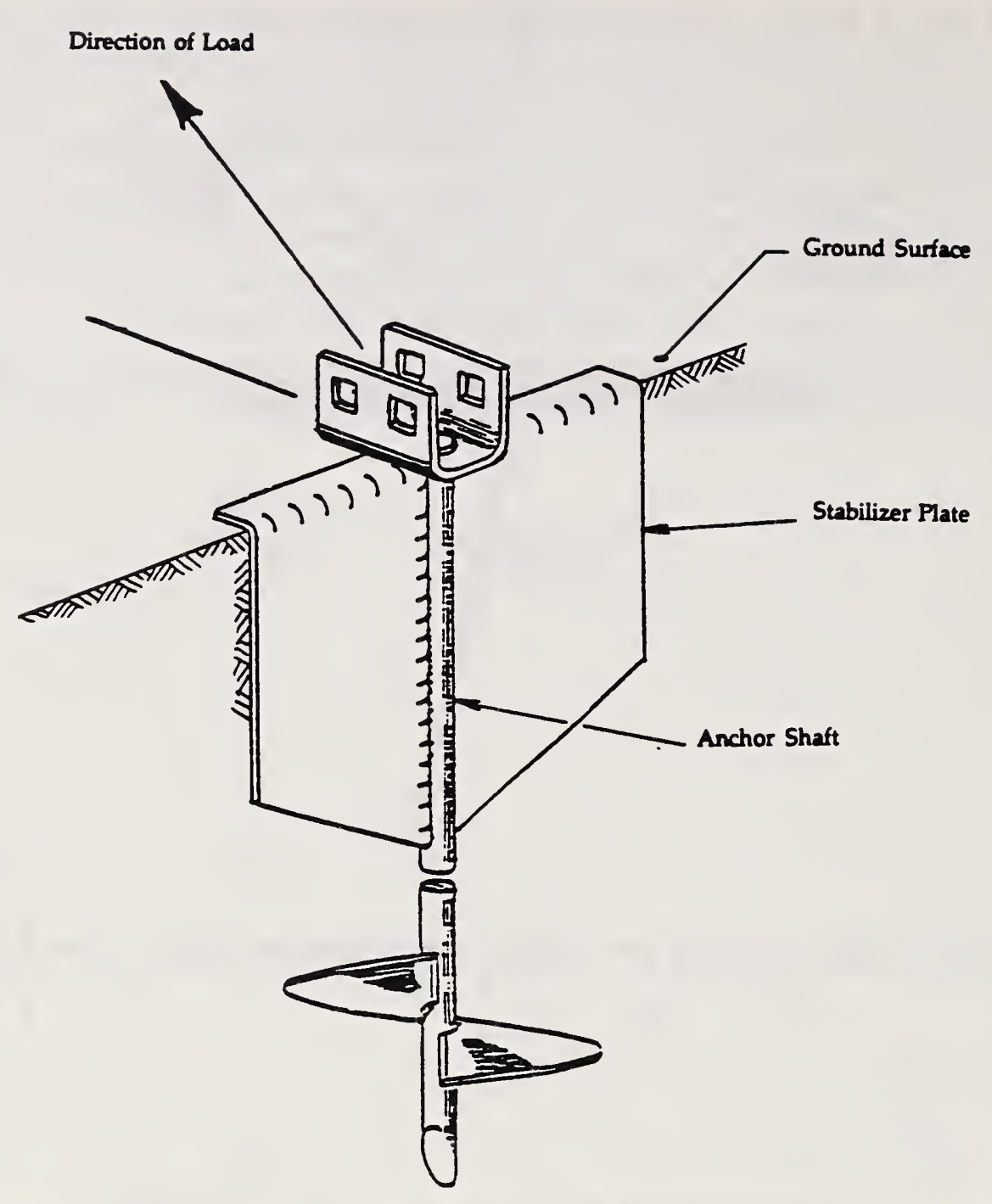

Figure 11. Typical soil anchor with stabilizer plate (Pearson et al. 1991)

A total of 31 anchors were tested with $\beta_{1}=45$ degrees and $\beta_{2}=105$ degrees. The angles selected for load application and anchor inclination were considered to be representative of current soil anchor installation practice. Some anchors were tested with bare anchor shafts, but the majority of tests were conducted with a $254 \mathrm{~mm}$ deep by $305 \mathrm{~mm}$ wide (10 x $12 \mathrm{in}$.) stabilizer plate installed flush with the ground surface and in contact with the anchor shaft. A typical soil anchor with a stabilizer plate is shown in Figure 11.

It was not possible to install the anchors to full depth in every case and those anchors have been excluded from the summary of results listed in Table 8. Also excluded from Table 8 are certain test results classified as "data outliers" that ranged from a low of $0.16 \mathrm{kN}(35 \mathrm{lbf})$ to a high of $15.12 \mathrm{kN}(3,400 \mathrm{lbf})$ at a horizontal displacement of $102 \mathrm{~mm}(4 \mathrm{in})$. The effect of including these outliers is to almost double the COV. Mean resistances and the corresponding standard deviations are shown in Figure 12 along with the ANSI A225.1 requirements. 
Table 8. Results of Field Pull-Out Tests on Fully Embedded Soil Anchors.

$$
\beta_{1}=45 \text { degrees } \beta_{2}=105 \text { degrees (Pearson et al. 1991) }
$$

\begin{tabular}{|c|c|c|c|c|c|c|}
\hline \multirow[b]{2}{*}{ LOADS: } & \multicolumn{3}{|c|}{$\begin{array}{l}\text { Without Stabilizer Plates } \\
\text { Number of Tests }=5\end{array}$} & \multicolumn{3}{|c|}{$\begin{array}{l}\text { With Stabilizer Plates } \\
\text { Number of Tests }=19\end{array}$} \\
\hline & $(\mathrm{kN})$ & (lbf) & $\mathrm{COV}$ & $(\mathrm{kN})$ & $(\mathrm{lbf})$ & $\mathrm{COV}$ \\
\hline $\begin{array}{l}\text { Load @ } 102 \text { mm (4 in.) } \\
\text { Horiz. Displacement }\end{array}$ & 2.94 & (662) & 0.18 & 3.58 & (805) & 0.41 \\
\hline Max. Load & 11.08 & $(2,490)$ & 0.26 & 11.47 & $(2,578)$ & 0.22 \\
\hline DISPLACEMENTS: & $(\mathrm{mm})$ & (in.) & $\mathrm{COV}$ & $(\mathrm{mm})$ & (in.) & $\mathrm{COV}$ \\
\hline Max. Horiz. Displacement & 287 & (11.3) & 0.17 & 409 & $(16.1)$ & 0.26 \\
\hline Max. Virt. Displacement & 81 & (3.2) & 0.63 & 130 & (5.1) & 0.57 \\
\hline
\end{tabular}

Inclined Loads on Anchors

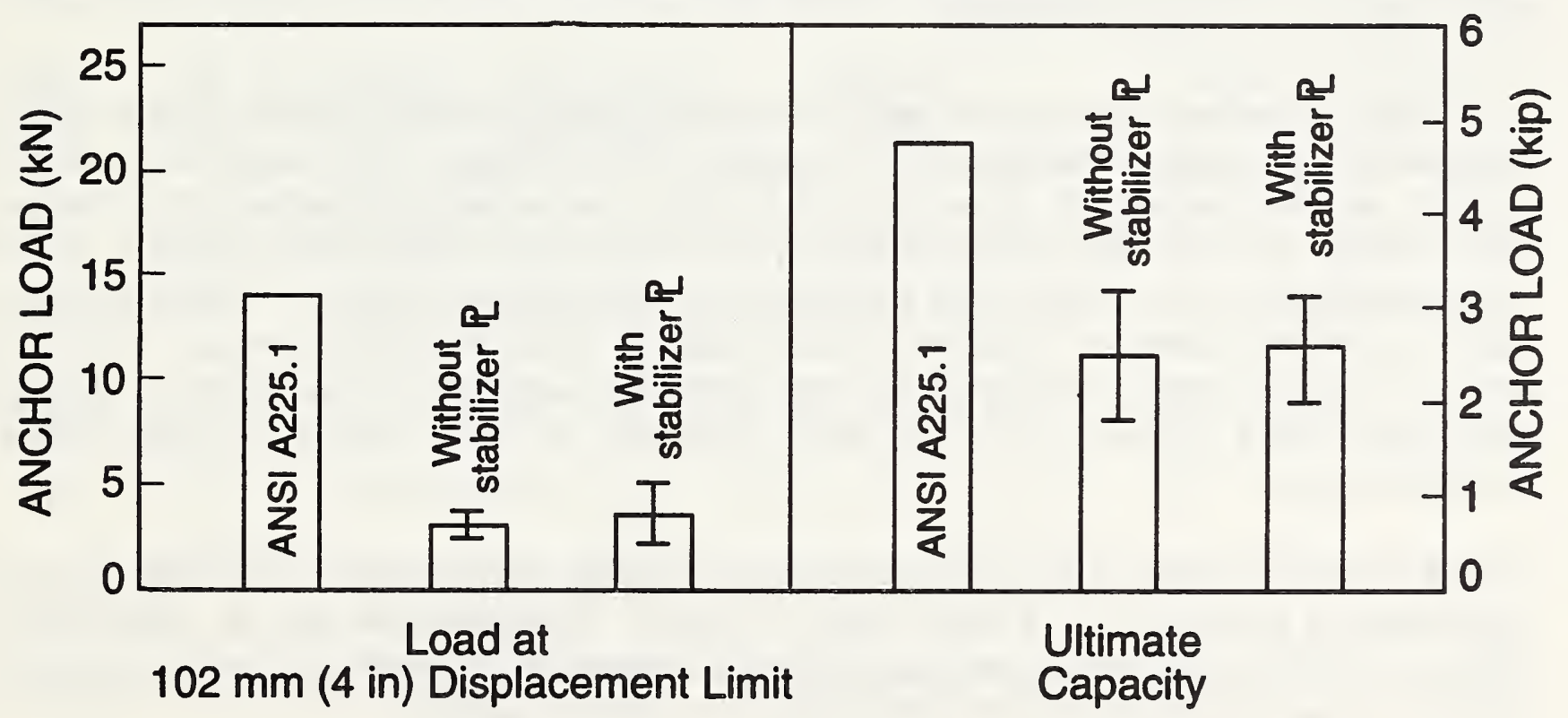

Figure 12. Anchor pull-out capacities. $\beta_{1}=45$ degrees $\beta_{2}=105$ degrees (Pearson et al. 1991) 
It is seen from Figure 12 that those anchors without stabilizer plates developed only about 21 percent of the required resistance at the horizontal displacement limit of $102 \mathrm{~mm} \mathrm{(4} \mathrm{in.),} \mathrm{and}$ the use of stabilizer plates resulted in only a marginal improvement ( 26 percent of required resistance). An additional problem with stabilizer plates is the large variation in resistance ( $\mathrm{COV}=0.41$ at the limiting horizontal displacement) that must be accounted for when assigning an allowable working load or resistance factor. Even at maximum horizontal displacement, of the order of 250 to $500 \mathrm{~mm}$ ( 10 to $20 \mathrm{in}$.), the anchors developed only about 80 percent of the required minimum working load of $14.01 \mathrm{kN}(3,150 \mathrm{lbf})$.

\subsection{NBS Studies of Soil Anchor Pull-Out Capacity}

The field test results described above are in general agreement with the earlier work of Yokel et al. (1982) at the National Bureau of Standards (NBS - now NIST) in which a comprehensive test program was carried out on soil anchors installed at three sites classified as silt, sand and clay. The anchors used in these tests included $152 \mathrm{~mm}(6 \mathrm{in}$.) single-helix and $102 \mathrm{~mm}(4 \mathrm{in}$.) double-helix anchors as well as three types of swivel anchors. A total of 232 pull-out tests were conducted under loading conditions that included axial and inclined pull on vertical and inclined anchors installed to their full depth, and axial pull on anchors installed at various depths ranging from 305 to $1,220 \mathrm{~mm}$ ( 1 to $4 \mathrm{ft}$ ). Loading included monotonic tests, monotonic tests with several intermediate cycles of unloading and reloading, and cyclic tests. The tests were carried to complete withdrawal and several anchors were tested under submerged conditions. In addition, the pull-out tests were correlated with determinations of soil properties by in-situ and laboratory tests. The in-situ tests included soil test probe (STP) readings, standard penetration tests (SPT), and the measurement of anchor installation torque. Since they constitute by far the largest portion of the NBS database, only those tests conducted using the $152 \mathrm{~mm}(6 \mathrm{in}$.) singlehelix anchors are referred to herein.

In general, the pull-out capacities of vertically installed, axially loaded $102 \mathrm{~mm}(4 \mathrm{in}$.) doublehelix anchors were approximately half the capacities of the $152 \mathrm{~mm}(6 \mathrm{in}$.) single-helix anchors similarly installed and loaded. Note that the total plate area and depth of embedment of doublehelix anchors are less than that provided by $152 \mathrm{~mm}(6 \mathrm{in}$.$) single-helix anchors. Some$ mechanical failures of anchors were observed during the testing program. Generally, these failures involved either the U-connection/rod weld or the helix plate/rod weld. For those anchors that were totally withdrawn or were otherwise uncovered, it was observed that the protective coating (paint) was either badly damaged or totally removed during anchor installation.

In both size and geometry, the $152 \mathrm{~mm}(6 \mathrm{in}$.) single-helix anchors used in the NBS tests are comparable to products 2, 5, 6 and 9 listed in Table 6. Representative load vs. displacement diagrams for vertically installed and axially loaded anchors in silt, sand and clay are shown in Figure 13, and test results for this configuration are listed in Table 9. 


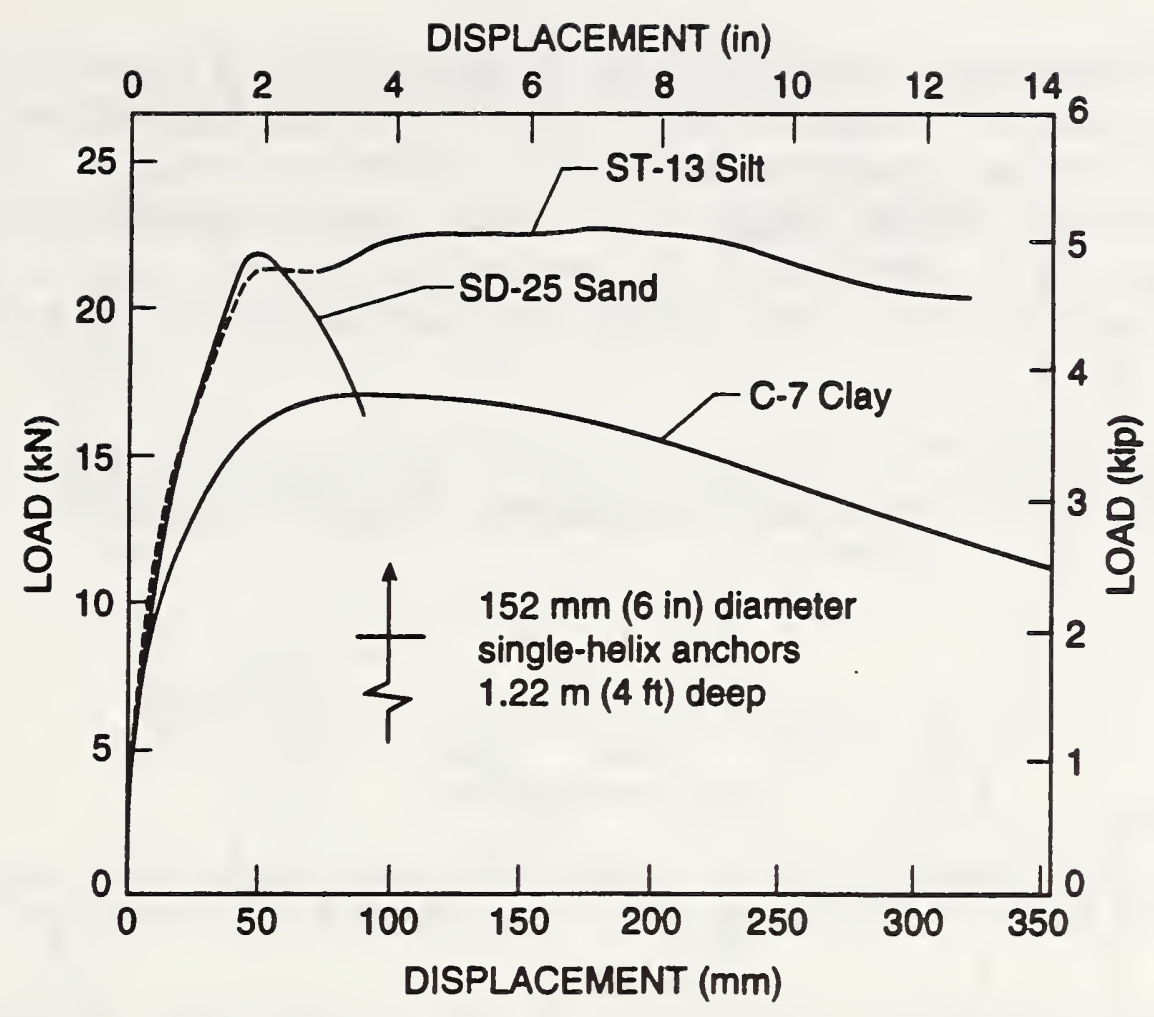

Figure 13. Typical load-displacement characteristics for fully embedded soil anchors in silt, sand and clay. $\beta_{1}=90$ degrees $\beta_{2}=90$ degrees (Yokel et al. 1982)

Table 9. Results of Field Pull-Out Tests on Fully Embedded Soil Anchors.

$\beta_{1}=90$ degrees $\beta_{2}=90$ degrees (Yokel et al. 1982)

Soil No. of Load @ 51 mm (2 in.)

Type Tests Vertical Displacement

$(\mathrm{kN}) \quad(\mathrm{lbf}) \quad \mathrm{COV}$
Ultimate

Load

$(\mathrm{kN}) \quad(\mathrm{lbf})$
Maximum Vertical

Displacement
Silt (1) 11
$19.10(4,295) \quad 0.20$
$23.01(5,173)$
0.10
182
(7.17) $\quad 0.53$
Silt (2) $\quad 5 \quad 10.32(2,320) \quad 0.40$
$16.19(3,640) 0.17$
280
(11.04) 0.35
Sand (1) 6
$19.96(4,488) \quad 0.13$
$22.52(5,063) \quad 0.13$
97
(3.82) $\quad 0.35$
Sand (2) 3
$22.68(5,100) \quad 0.17$
$26.48(5,953) \quad 0.18$
110
(4.35) $\quad 0.25$
Clay (1) $\quad 3 \quad 13.64(3,067) \quad 0.22$
$15.27(3,433) \quad 0.16$
148
(5.83) $\quad 0.49$
(1) Moist
(2) Wet 
Test results are compared with the requirements of ANSI A225.1 in Figure 14. The dashed lines in the figure represent the mean load at $51 \mathrm{~mm}(2 \mathrm{in}$.) vertical displacement, and the solid lines represent the mean and standard deviation of the ultimate load capacity. It is seen that in only one case (wet sand) did the withdrawal resistance meet the requirement for a limiting vertical displacement of $51 \mathrm{~mm}(2 \mathrm{in}$.). For wet silt and for clay, even the ultimate load capacity failed to meet the ANSI A225.1 working load requirement of $14.01 \mathrm{kN}(3,150 \mathrm{lbf})$.

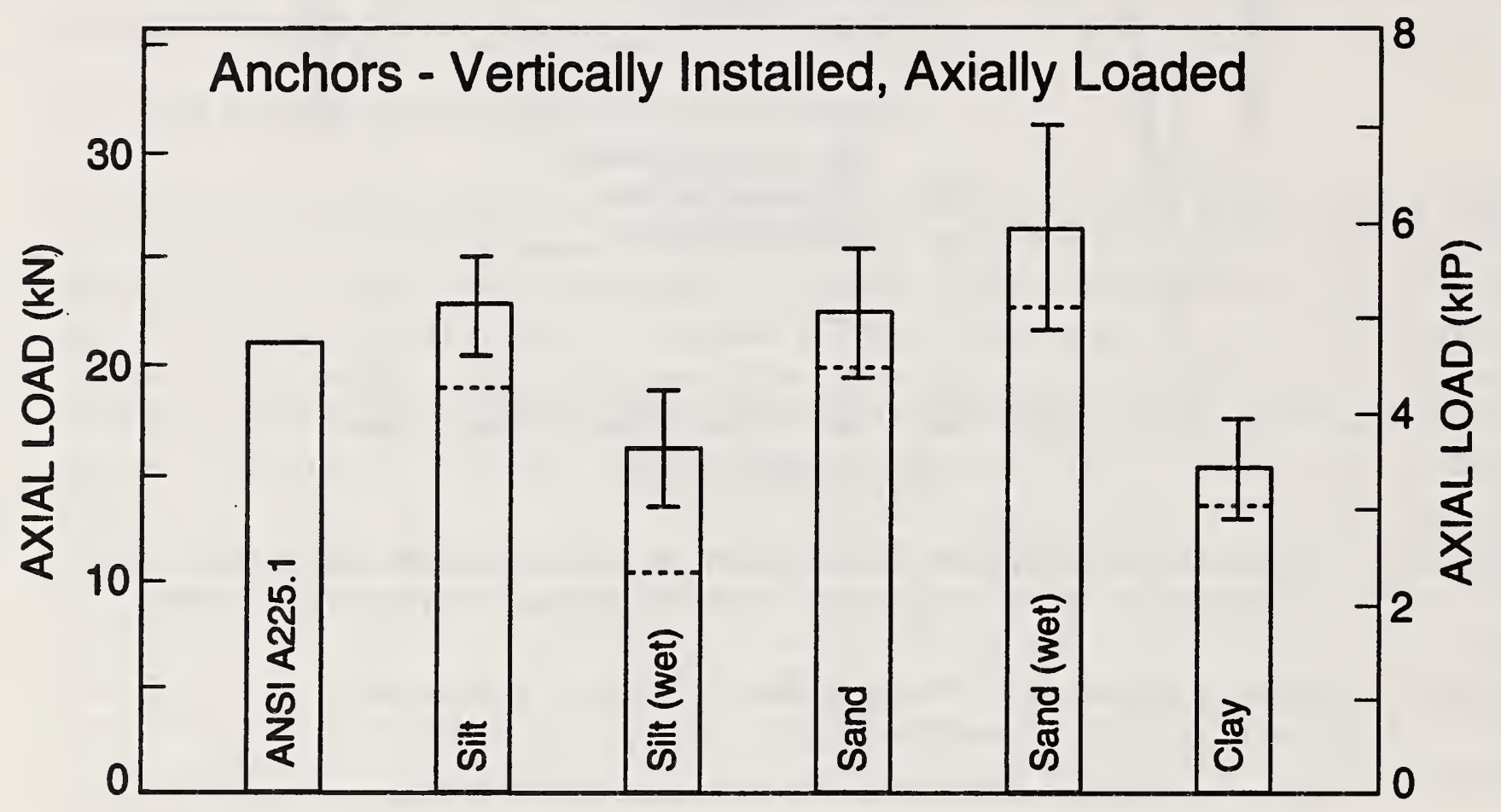

Figure 14. Results of field pull-out tests on fully embedded soil anchors. $\beta_{1}=90$ degrees $\beta_{2}=90$ degrees (Yokel et al. 1982)

Note: Dashed lines denote loads at limiting vertical displacement Solid lines denote ultimate load capacity

Typical load vs. displacement diagrams for vertically installed anchors with inclined loads applied at $\beta_{1}=40$ degrees are shown in Figure 15, and test results for various combinations of $\beta_{1}$ and $\beta_{2}$ are listed in Table 10. Each entry in Table 10 is based on the results of three tests. 


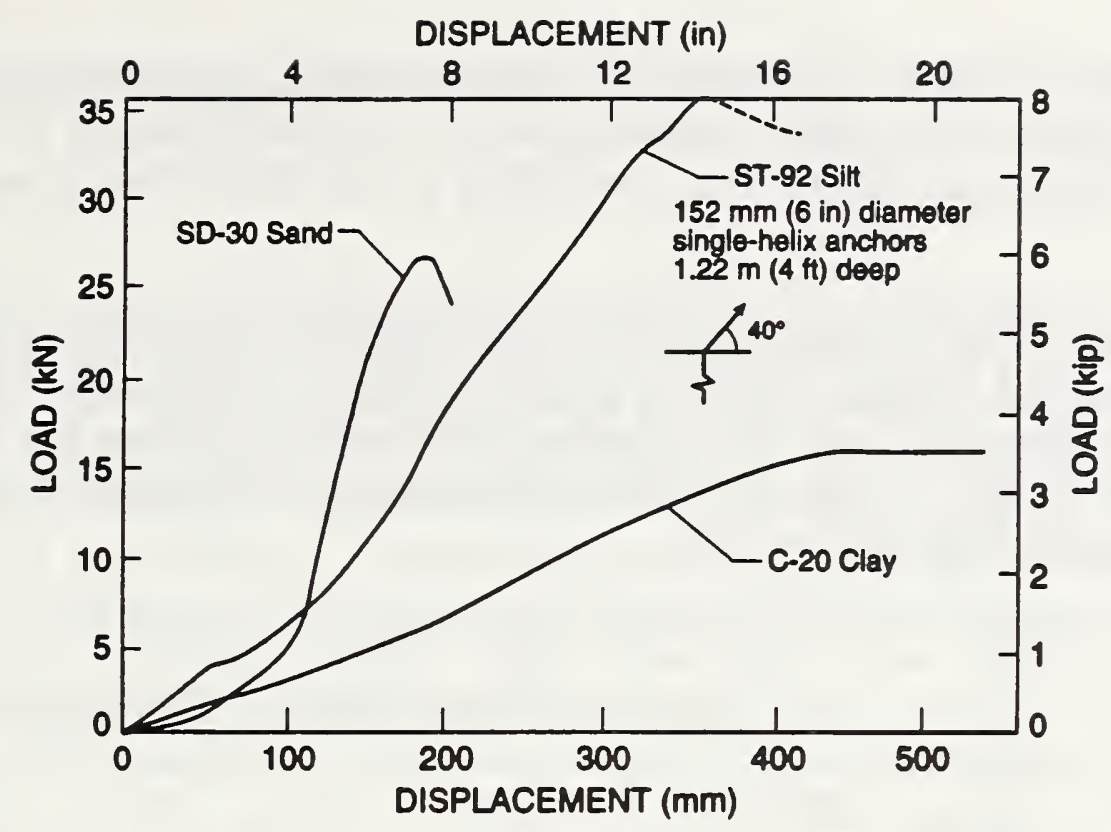

Figure 15. Typical load-displacement characteristics for fully embedded soil anchors in silt, sand and clay. $\beta_{1}=40$ degrees $\beta_{2}=90$ degrees (Yokel et al. 1982)

Table 10. Results of Field Pull-Out Tests on Soil Anchors Installed and Loaded at Various Angles (Yokel et al. 1982)

Soil Angles Load @ 102 mm (4 in.) Ultimate

Type $\beta(1) / \beta(2)$ Horiz. Displacement Load Displacement (degrees) (kri) (lbf) $\mathrm{COV} \quad(\mathrm{kN}) \quad(\mathrm{bf}) \quad \mathrm{COV} \quad(\mathrm{mm}) \quad$ (in.) $\mathrm{COV}$

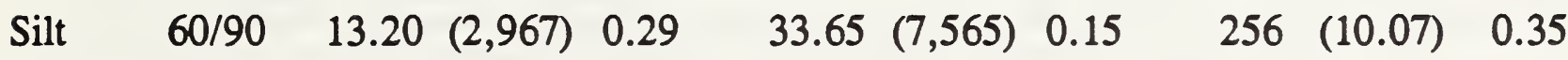

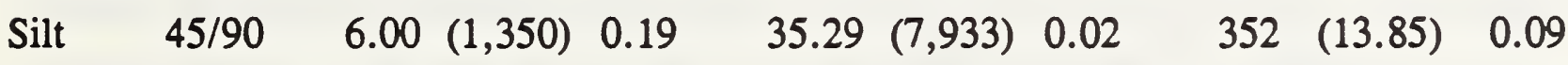

$\begin{array}{llllllllll}\text { Sand } \quad 40 / 90 & 11.49 & (2,583) & 0.20 & 27.52 & (6,187) & 0.05 & 231 & (9.08) & 0.07\end{array}$

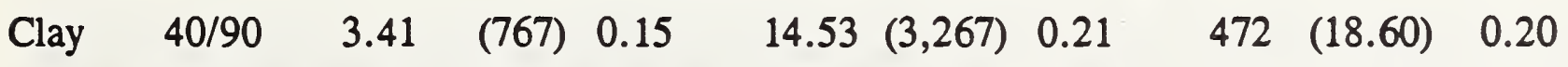

$\begin{array}{llllllllll}\text { Silt } & 60 / 135 & 1.93 & (433) & 0.13 & 15.07 & (3,387) & 0.13 & 639 \cdot(25.15) & 0.04\end{array}$

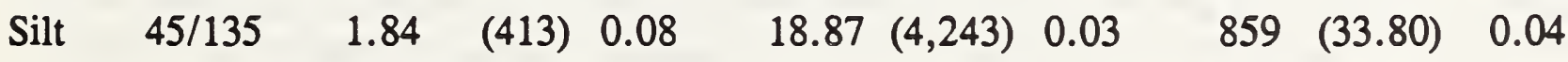

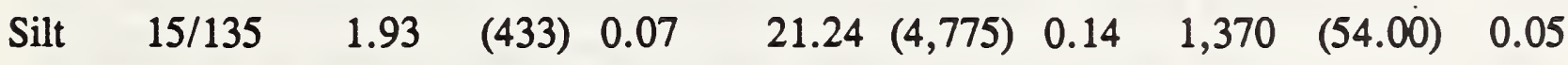

Notes: Each case based on 3 tests. All tests conducted under moist soil conditions 
By comparing Figures 13 and 15 for vertically installed anchors, it is seen that even though the anchor heads experience much larger displacements, the ultimate capacities of anchors loaded at 40 degrees with the horizontal equal or substantially exceed the ultimate capacities of axially loaded anchors.

The test results listed in Table 10 are compared with the requirements of ANSI A225.1 in Figure 16 where the mean and standard deviation of applied load are shown for both the limiting horizontal displacement of $102 \mathrm{~mm}$ (4 in.) (dashed lines) and the ultimate withdrawal capacity (solid lines). The entries on each bar indicate the angle of applied load and the angle of installation $\left(\beta_{1} / \beta_{2}\right)$ as defined in Figure 9.

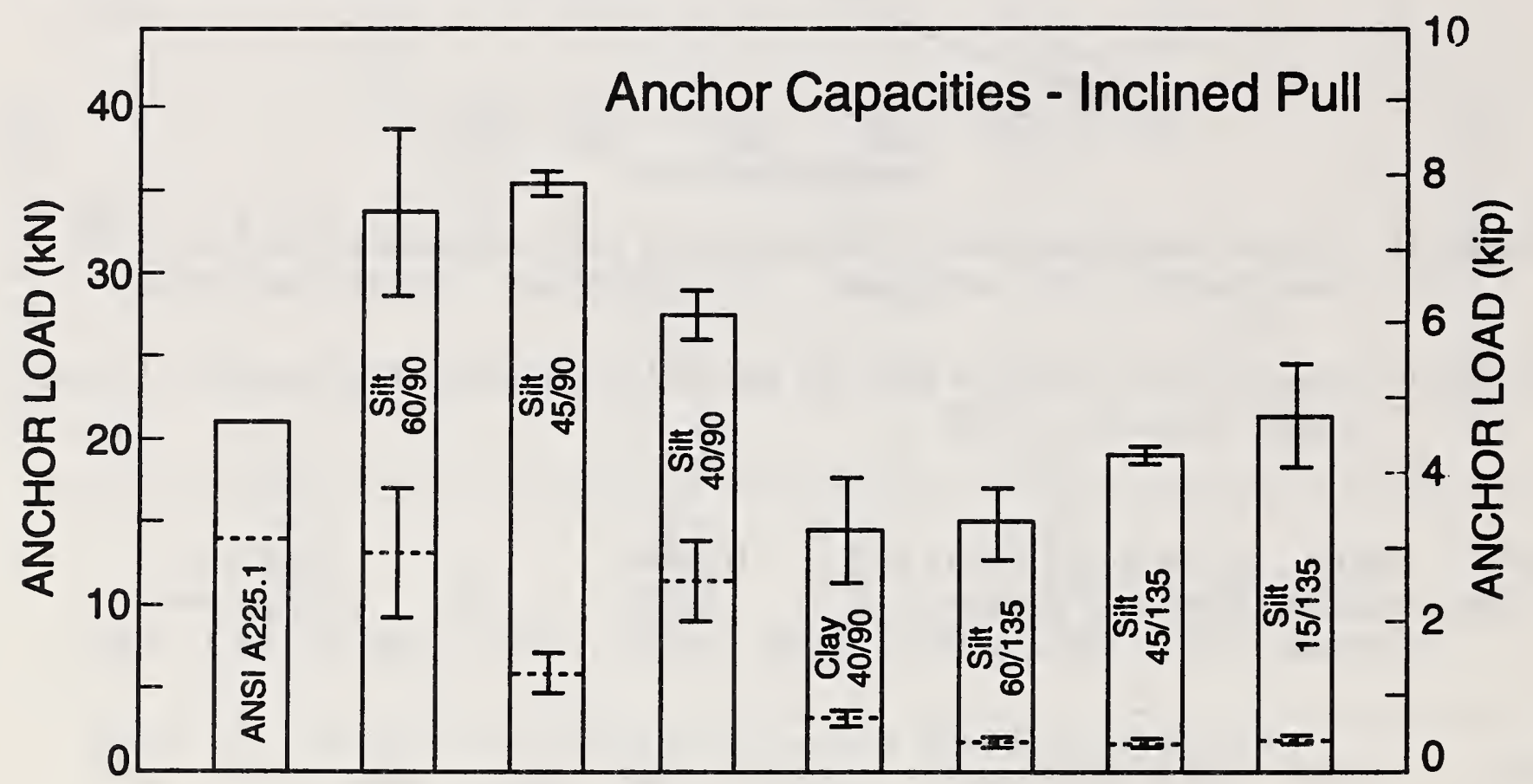

Figure 16. Results of field pull-out tests on soil anchors installed and loaded at various angles (Yokel et al. 1982)

Note: Dashed lines denote loads at limiting horizontal displacement Solid lines denote ultimate load capacity

It can be seen from Figure 16 that none of the load/installation configurations listed in Table 10 meet the ANSI A225.1 limitation on horizontal displacement at the prescribed working load of $14.01 \mathrm{kN}(3,150 \mathrm{lbf})$. In fact, those anchors installed in silty soil with $\beta_{2}=135$ degrees developed only about 14 percent of the required working load at a horizontal displacement of $102 \mathrm{~mm}$ ( 4 in.). Compare this with values of 21 to 26 percent obtained by Pearson et al. (1991) for loose to medium dense sand. Given this abysmal performance of conventional soil anchors under the action of inclined loads, it is unfortunate that the committee responsible for NCSBCS A225.1 chose to delete the displacement limitations altogether rather than address the problem directly. Furthermore, a simple and workable solution to the problem was proposed more than 10 years ago (Yokel et al. 1982), a fact that makes the current situation all the more inexcusable. 


\subsection{NEEDED IMPROVEMENTS}

\subsection{General}

It is clear from the field test results obtained by Pearson et al. (1991) and by Yokel et al. (1982) that conventional shallow soil anchors, coupled with traditional installation practice, do not provide sufficient withdrawal resistance to meet the stated requirements of the MHCSS or of ANSI A225.1. Equally important is the fact that the large horizontal displacements required to develop acceptable levels of anchor resistance are incompatible with the displacement limits needed to ensure pier stability. Compared with the load capacities of other elements of the traditional anchoring system, horizontal displacement of the anchor head and anchor withdrawal capacity are most definitely the weak links in the system (see Figures 12 and 16). The assumption that conventional shallow soil anchors, even when provided with stabilizer plates, can meet the working load and overload conditions defined in the MHCSS and in ANSI A225.1 is an exercise in wishful thinking. Either this traditional approach to the anchoring of manufactured homes as a means of providing windstorm protection must be abandoned, or the method of installation must be revised to ensure adequate windstorm protection.

\subsection{Shortcomings of the Traditional Approach}

In principle, the proper choice of soil anchor and its estimated pull-out resistance for a given site can be made on the basis of standard penetration test (SPT) blow count and/or soil test probe (STP) torque readings. As was noted earlier, Yokel et al. (1982) obtained such measurements, in addition to installation torque and laboratory tests, to characterize the soil shear strength in the course of their anchor pull-out studies. As can be seen from Figure 17, there is no obvious correlation between SPT and STP readings for silty soils. Among the reasons for this lack of correlation is the fact that the SPT cannot deliver repeatable energy levels at shallow soil depths.

In Figure 18, the withdrawal resistance of vertically installed single-helix anchors is plotted against STP torque measured at the installed depth of the helix plate. $\mathrm{Q}_{\mu}$ is the ultimate load capacity and $P_{2 v}$ is the load at $51 \mathrm{~mm}(2 \mathrm{in})$ vertical displacement. Although there is a clear correlation between STP torque and withdrawal resistance, the scatter in the data is so large (typically a factor of $\times 2$ ) that the method becomes impractical for the estimation of pull-out capacity. However, the most serious problem with traditional soil anchor systems is that of excessive horizontal displacements when the anchors must be relied upon to resist inclined loads. 


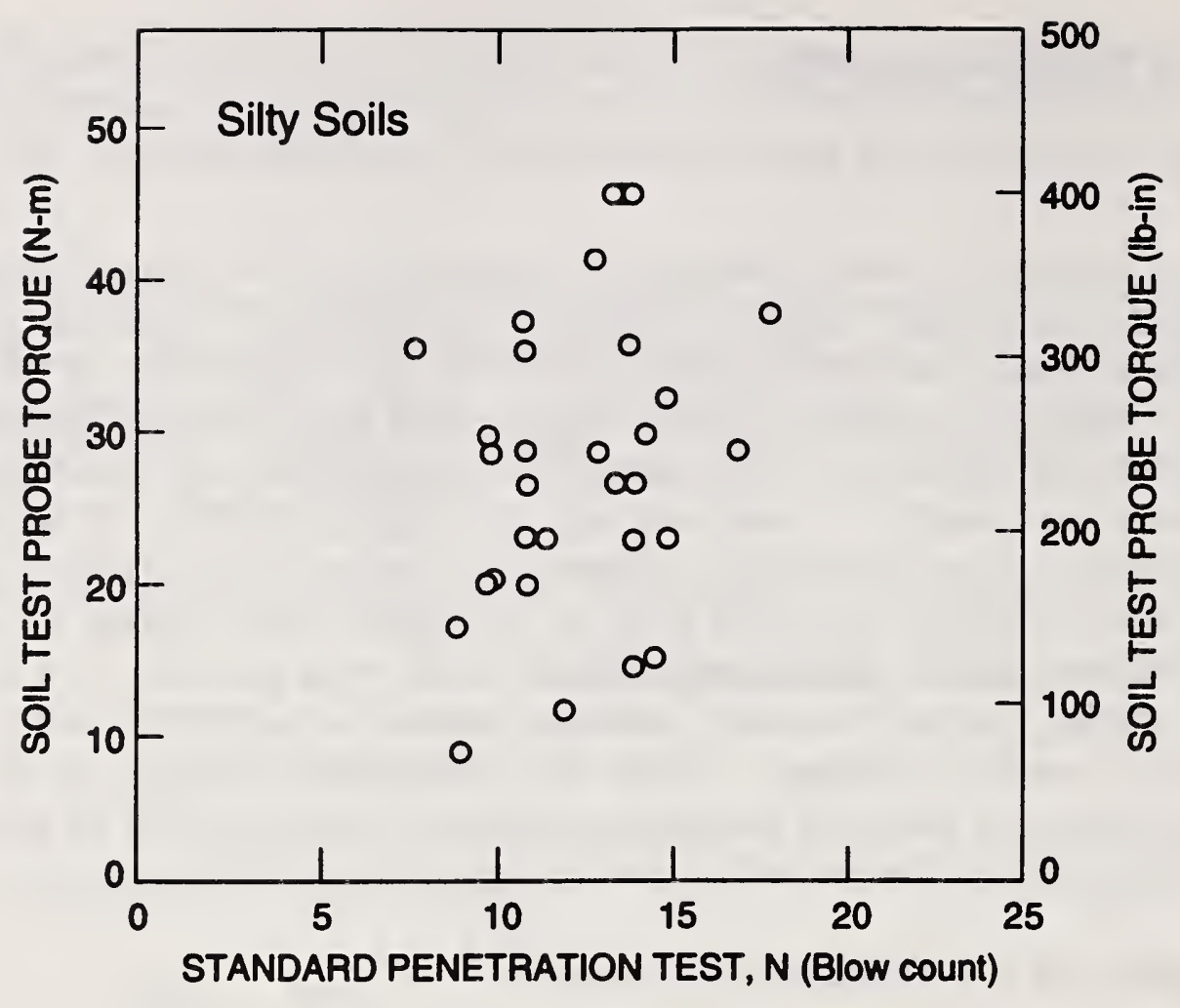

Figure 17. Correlation between SPT blow count and STP torque reading for silty soil (Yokel et al. 1982)

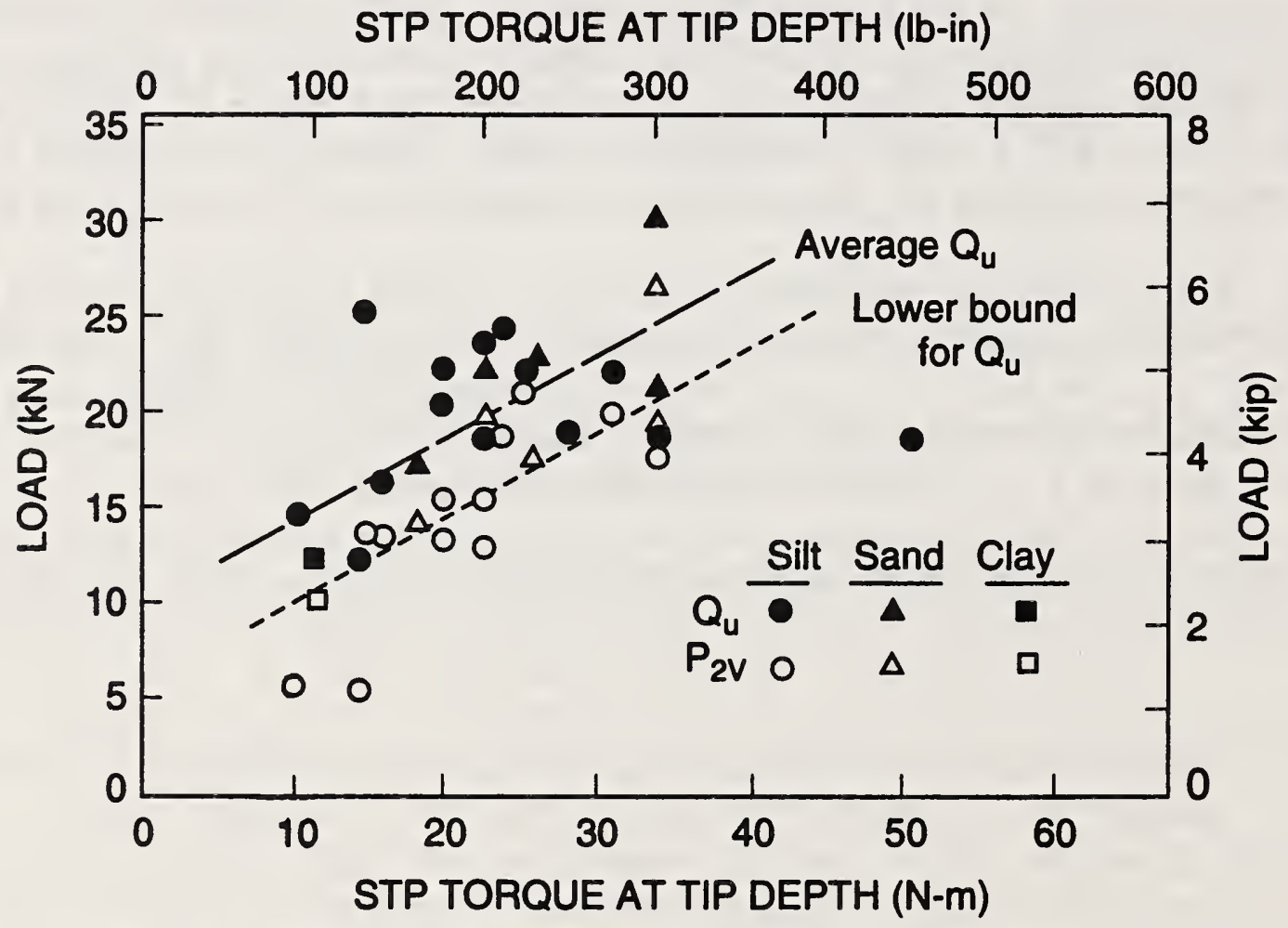

Figure 18. Correlation between STP torque reading and withdrawal resistance of fully embedded soil anchors. $\beta_{1}=90$ degrees $\beta_{2}=90$ degrees (Yokel et al. 1982) 


\subsection{A New Approach to Anchor Installation}

Recognizing the inadequacy of conventional soil anchors at shallow depths and the limitations of the SPT and STP as a means for estimating pull-out capacity, Yokel et al. (1982) proposed a new approach that involves the preloading of soil anchors. The essence of preloading is shown in Figure 19 where a vertically installed anchor is unloaded and reloaded in incremental load steps up to failure of the helix-to-rod weld. Normally, this anchor would have failed the ANSI A225.1 displacement limit at an inclined load of roughly $5 \mathrm{kN}$ (1 kip). However, by the 5 th load cycle, the reloading modulus is approximately $1.05 \mathrm{kN} / \mathrm{mm}(6,000 \mathrm{lbf} /$ in) or more than 7 times the requirement of ANSI A225.1. With the high reloading modulus, it is possible to take advantage of the higher ultimate capacities inherent in vertically installed anchors subjected to inclined loads. Note that several unloading and reloading cycles are shown in Figure 19 to illustrate the development of horizontal stiffness. The characteristics of the 5th cycle (or any cycle) could have been obtained without the performing the intermediate cycles. To accomplish anchor preloading, Yokel et al. (1982) proposed the scheme shown in Figure 20.

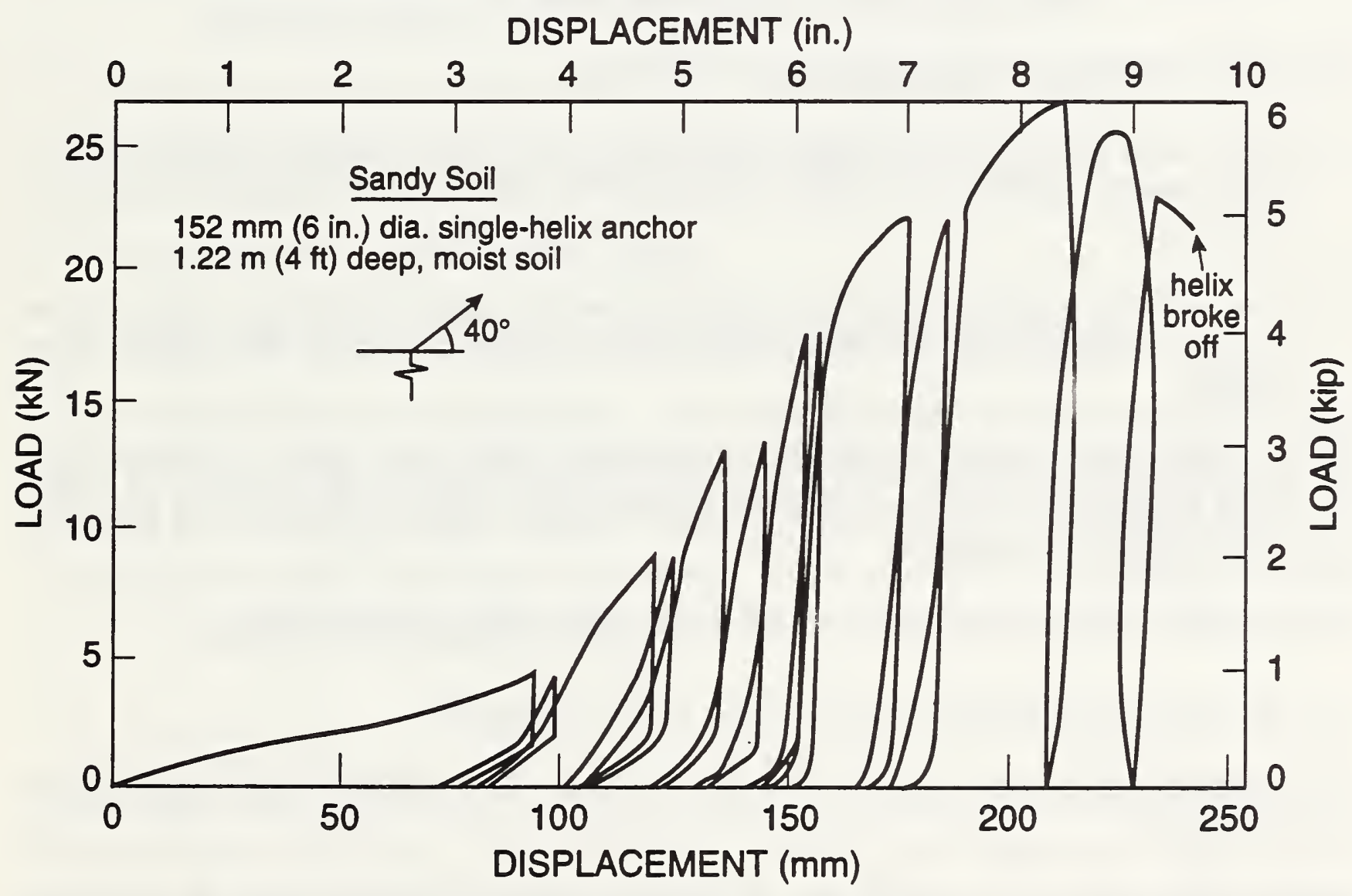

Figure 19. Inclined pull-out test on a fully embedded single-helix anchor in sand. $\beta_{1}=40$ degrees $\beta_{2}=90$ degrees (Yokel et al. 1982) 


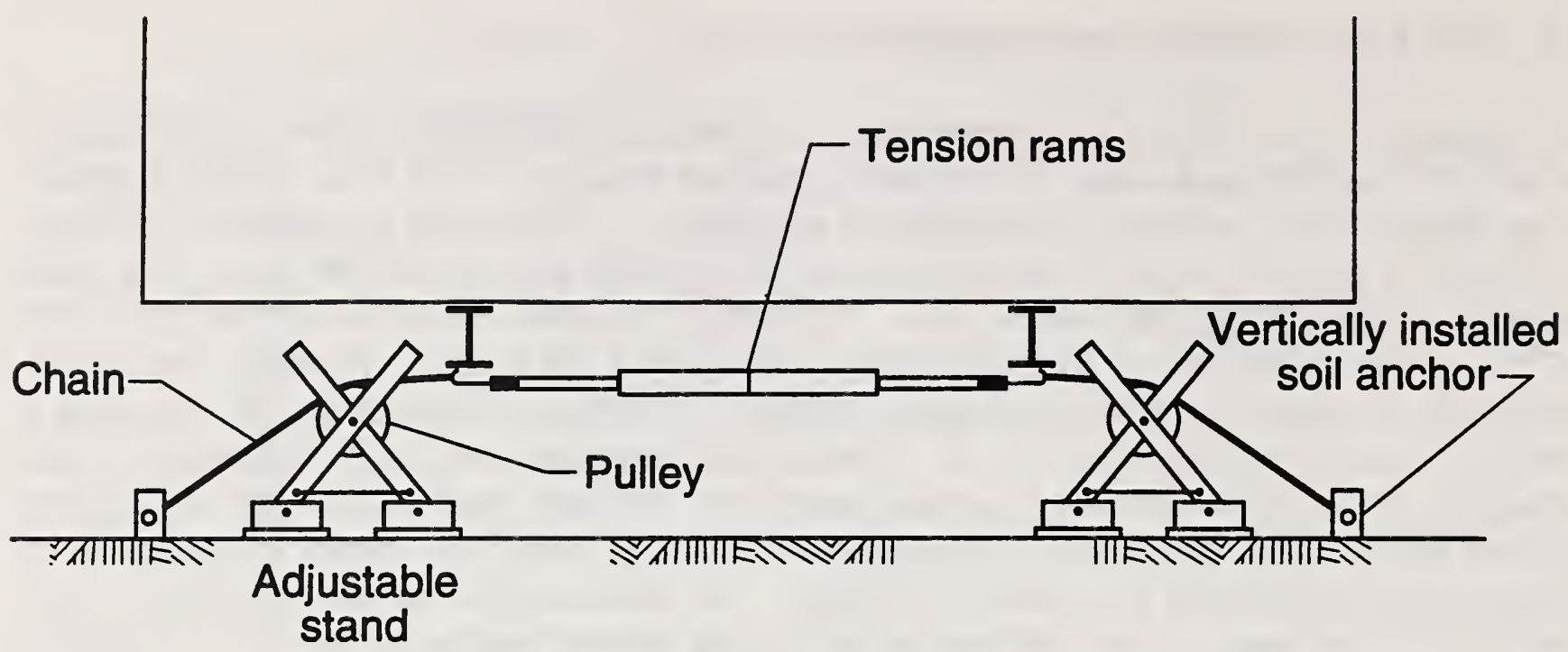

Figure 20. Scheme proposed by Yokel et al. (1982) for the preloading of vertically installed soil anchors with inclined loads

Among the advantages of preloading are the following:

- There is no need to rely on lateral stabilizing devices which, because of their shallow depth, develop relatively low mean resistance and are associated with large coefficients of variation.

- Because of the relatively large horizontal displacements under preloading, anchors can be installed vertically with the manufactured home in place as is done now with inclined anchors.

- In general, the re-loading displacements will be far smaller than those allowed by ANSI A225.1, thereby increasing pier stability and allowing a larger percentage of the drag load to be resisted by the piers.

- The helix plates can be installed to full depth, thus increasing their efficiency.

o The uncertainties inherent to the SPT and STP are removed.

- The preloading system involves simple hardware that does not require a high degree of skill to operate.

Although preloading of soil anchors was proposed by Yokel and his co-workers more than 10 years ago, it is surprising that no real interest in this approach has been shown by installers of manufactured homes or by building officials. Certainly this approach has far more merit than does the decision by the NCSBCS A225.1 committee to remove from the standard all reference to limitations on anchor head displacement. 


\subsection{Recommended Installation Procedure}

The recommended procedure for determining anchor spacing and points of installation is as follows:

1. Establish the minimum number of diagonal ties required based on the length of the manufactured home, the basic wind speed, and a maximum tie capacity of $16.90 \mathrm{kN}(3,800$ lbf).

\section{EXAMPLE:}

Length of manufactured home $=21.34 \mathrm{~m} \quad(70 \mathrm{ft})$

Basic wind speed $=35.76 \mathrm{~m} / \mathrm{s} \quad(80 \mathrm{mph})$

From Table 3, diagonal tie factored load $=4.83 \mathrm{kN} / \mathrm{m} \quad(331 \mathrm{lbf} / \mathrm{ft})$

Maximum tie spacing $=16.90 / 4.83=3.50 \mathrm{~m} \quad(3,800 / 331=11.5 \mathrm{ft})$

Minimum number of ties $=21.34 / 3.50=6 \quad(70 / 11.5=6)$

2. Estimate the horizontal displacement of the anchor head under preload.

3. Determine desired final head location for a tie angle of 45 degrees.

4. Install first anchor pair and apply preload.

5. Position next anchor pair on basis of observed anchor head displacement.

To account for friction in the preloading system and the possibility that the diagonal tie angle will exceed 45 degrees (thus inducing higher loads in the tie and anchor), the preload should be taken as 1.10 times the factored loads indicated in Table 3. If the soil conditions and anchor type will not develop sufficient resistance, then the anchor spacing must be determined on the basis of anchor capacity rather than on the capacity of the diagonal tie. Whatever the case may be, the sum of the preloads should exceed by 10 percent the product of the factored tie load (Table 3 ) and the length of the home $\left(T_{D}\right)(L)$.

With reference to Table 3-2.7 of ANSI A225.1, the average spacing of diagonal ties (alternate method without vertical ties) is $4.70 \mathrm{~m}$ (15.5 ft) for Zone I and $2.45 \mathrm{~m}$ (8.0 ft) for Zone II. For a basic wind speed of $44.7 \mathrm{~m} / \mathrm{s}(100 \mathrm{mph})$ the required tie spacing for the ASCE 7-88 factored loads becomes $16.90 / 7.55=2.24 \mathrm{~m}(7.35 \mathrm{ft})$. At basic wind speeds above this level the decreased anchor spacing will be accompanied by significant overlapping of the cones of influence, and other approaches to windstorm protection will need to be considered. 


\subsection{MAJOR FINDINGS AND RECOMMENDATIONS}

\subsection{General}

The risk of structural failure implicit in the wind load provisions of the MHCSS in effect at the time of Hurricane Andrew has been compared with that of ASCE 7-88 for selected locations in the United States. In arriving at these comparisons, it was necessary to make certain assumptions regarding the mean and variation of structural resistance associated with contemporary construction. This study also examined traditional practice for providing windstorm protection for manufactured homes, the forces involved, and the resistance likely to be provided by anchoring systems that rely on steel strapping and shallow soil anchors.

\subsection{Major Findings}

The major findings resulting from this study can be summarized as follows:

- For a 10-yr exposure, the risk of failure in high winds for structures designed in accordance with the wind load requirements of the MHCSS in effect at the time of Hurricane Andrew is of the order of 10 times the risk of failure expected for structures designed in accordance with the wind load provisions of ASCE 7-88.

- Traditional soil anchor installation practice does not provide the level of windstorm protection suggested by the provisions of the MHCSS or of ANSI A225.1, and major changes in the design requirements and installation practice are needed.

- Based on extensive laboratory and field studies referenced herein, the expectations of the MHCSS and of ANSI A225.1 for the performance of traditional anchoring systems far exceed the levels of resistance that these systems can reasonably be expected to provide.

o The large horizontal displacements required to develop acceptable levels of anchor resistance are incompatible with the displacement limits needed to ensure pier stability.

- Because of their shallow depth, stabilizer plates exhibit low mean resistance and high variability which makes them minimally effective in increasing the lateral resistance of soil anchors subjected to inclined loads.

- Preloading of soil anchors can remove much of the uncertainty associated with traditional installation practice and allows one to take advantage of the higher ultimate capacities inherent in vertically installed anchors subjected to inclined loads.

- If the diagonal (frame) ties and associated soil anchors are properly designed and installed, there are no obvious benefits to be derived from the use of vertical ties other than to possibly resist buoyancy forces during flooding. 
o Protective coatings currently used on soil anchors are badly damaged or totally removed during the installation process.

- For basic wind speeds above $44.7 \mathrm{~m} / \mathrm{s}(100 \mathrm{mph})$ the cones of influence for adjacent soil anchors will increasingly overlap, and other approaches to windstorm protection in hurricane-prone regions need to be considered.

\subsection{Recommendations}

The following recommendations are made on the basis of the above findings:

- Anchoring systems for windstorm protection should be designed and installed on the basis of diagonal ties alone rather than the current practice of using a combination of diagonal and vertical ties.

- Conventional soil anchors should be installed vertically so that the helix plate is located at maximum depth.

- Conventional soil anchors need to be preloaded to obtain sufficient system stiffness and to take advantage of the higher ultimate capacity of vertically installed anchors subjected to inclined loads.

- The decision to delete soil anchor displacement limitations from the provisions of ANSI A225.1-1987 (Manufactured Home Installations) should be reversed, and rational criteria for allowable displacements need to be established.

- Additional studies are needed to establish the in-service strength of cold-rolled steel strapping used for frame ties.

- Protective coatings for soil anchors need to be improved to resist damage and/or removal during anchor installation.

- A new approach to providing windstorm protection for manufactured homes located in hurricane-prone regions needs to be developed. 


\subsection{REFERENCES}

ASCE (1990). Minimum Design Loads for Buildings and Other Structures, ASCE 7-88, American Society of Civil Engineers, New York, NY, 94 pp.

ASTM (1993). "ASTM D 3953-91, Standard Specification for Strapping, Flat Steel and Seals." 1993 Annual Book of ASTM Standards, American Society for Testing and Materials, Philadelphia, PA, Vol. 15.09, pp 643-653.

Batts, M.E., Cordes, M.R., Russell, L.R., Shaver, J.R. and Simiu, E. (1980). "Hurricane Wind Speeds in the United States." NBS Building Science Series 124, National Bureau of Standards, Washington, DC, $41 \mathrm{pp}$.

Cook, N.J. (1985). The Designer's Guide to Wind Loading of Building Structures - Part 1. Butterworths, London, $371 \mathrm{pp}$.

Dewey, R.C. and Luebs, D.F. (1992). "Performance of Manufactured Housing Metal Roof Assemblies and Their Connections Under Simulated Wind Uplift Loads." Final Report - NAHB Research Center, Upper Marlboro, MD, 25 pp.

Ellingwood, B., Galambos, T.V., MacGregor, J.G. and Cornell, C.A. (1980). "Development of a Probability Based Load Criterion for American National Standard A58." NBS Special Publication 577, National Bureau of Standards, Washington, DC, pp 115.

Georgiou, P.N., Davenport, A.G. and Vickery, B.J. (1983). "Design Wind Speeds in Regions Dominated by Tropical Cyclones." Journal of Wind Engineering and Industrial Aerodynamics, Vol. 13, 139-152.

Gupta, A.K. and Moss, P.J. (Eds.) (1993). Guidelines for Design of Low-Rise Buildings Subjected to Lateral Forces. CRC Press, Inc., Boca Raton, FL, 286 pp.

HUD (1994). Final Rule - Manufactured Home Construction and Safety Standards on Wind Standards, Office of the Assistant Secretary for Housing, Dept. of Housing and Urban Development, Federal Register, Vol. 59, No. 10, 2456-2474.

MHCSS (1992). Manufactured Home Construction and Safety Standards, 24 CFR, Chapter XX, Pt. 3280, pp 196-223.

Marshall, R.D. (1993). "Wind Load Provisions of the Manufactured Home Construction and Safety Standards - A Review and Recommendations for Improvement." NISTIR 5189, National Institute of Standards and Technology, Gaithersburg, MD, 90 pp.

NAHB (1988). "Structural Tests of a Ceiling Diaphragm Construction for Manufactured Housing." Final Report - NAHB National Research Center, Upper Marlboro, MD, 25 pp. 
NCSBCS (1982). NCSBCS Standard for Manufactured Home Installations (Manufactured Home Sites, Communities and Set-ups) - ANSI A225.1-1992. National Conference of States on Building Codes and Standards, Inc., Herndon, VA, 57 pp.

NCSBCS (1987). NCSBCS Standard for Manufactured Home Installations (Manufactured Home Sites, Communities, and Set-ups). National Conference of States on Building Codes and Standards, Herndon, VA, 49 pp.

Pearson, J.E., Meinheit, D.F. and Longinow, A. (1991). "Testing of Soil Anchors and Strapping." Report No. WJE 901798, prepared for U.S. Dept. of Housing and Urban Development, WJE Associates, Inc., Northbrook, IL, 67 pp.

Reinhold, T.A., Vickery, P.J. and Powell, M.D. (1992). "Wind Speeds in Hurricane Andrew: Myths and Reality." American Concrete Institute Annual Convention, San Juan, PR, Oct. 26, 12 pp plus figures.

Russell, L.R. (1971). "Probability Distributions for Hurricane Effects." Journal of the Waterways, Harbors, and Coastal Engineering Division, American Society of Civil Engineers, New York, Vol. 97, No. WW1, pp 139-154.

SFBC (1988). South Florida Building Code, 1988 Ed., Vol. 1, Building and Zoning Department, Metropolitan Dade County, Miami, FL.

Simiu, E., Changery, M.J. and Filliben, J.J. (1979). "Extreme Wind Speeds at 139 Stations in the Contiguous United States." NBS Building Science Series 142, National Bureau of Standards, Washington, DC, $147 \mathrm{pp}$.

Vann, P.W. and McDonald, J.R. (1978). "An Engineering Analysis: Mobile Homes in Windstorms." Report prepared for Disaster Preparedness Staff, National Weather Service, NOAA, Silver Spring, Maryland. Institute for Disaster Research, Texas Tech University, Lubbock, TX, $145 \mathrm{pp}$.

Yokel, F.Y., Yancey, C.W.C. and Mullen, C.L. (1981). "A Study of Reaction Forces on Mobile Home Foundations Caused by Wind and Flood Loads." NBS Building Science Series 132, National Bureau of Standards, Washington, DC, 74 pp.

Yokel, F.Y., Chung, R.M., Rankin, F.A. and Yancey, C.W.C. (1982). "Load-Displacement Characteristics of Shallow Soil Anchors." NBS Building Science Series 142, National Bureau of Standards, Washington, DC, $147 \mathrm{pp}$. 


\section{ACKNOWLEDGMENTS}

For providing many helpful suggestions and numerous reference materials used in this study, the author wishes to thank Mr. William Freeborne of the Affordable Housing Research and Technology Division, Office of Research, Evaluation and Monitoring, and Mr. Richard Mendlen of the Manufactured Housing and Construction Standards Division, Office of Manufactured Housing and Regulatory Functions, U.S. Department of Housing and Urban Development. The author is indebted to Dr. John Gross of the Structures Division, Building and Fire Research Laboratory, NIST, and to Dr. Felix Yokel for reviewing the manuscript and for offering many constructive comments. 


\section{APPENDIX}

FACTORED TIE AND PIER FORCES PER UNIT LENGTH OF HOME

Assumptions:

$$
\begin{aligned}
& \mathrm{a}=2.134 \mathrm{~m}(7 \mathrm{ft}) \\
& \mathrm{b}=4.267 \mathrm{~m}(14 \mathrm{ft}) \\
& \mathrm{h}=2.438 \mathrm{~m}(8 \mathrm{ft}) \\
& \theta=45 \text { degrees }
\end{aligned}
$$

Dead load $=1.20 \mathrm{kPa}(25 \mathrm{psf})$

\section{MHCSS Zone I Factored}

Wind Loads: (See Table 2)

$$
\begin{aligned}
& P_{W}=1.08 \mathrm{kPa}(22.5 \mathrm{psf}) \\
& P_{R W}=0.65 \mathrm{kPa}(13.5 \mathrm{psf}) \\
& P_{R L}=0.65 \mathrm{kPa}(13.5 \mathrm{psf})
\end{aligned}
$$

$\sum F_{X}=0$

$$
\begin{aligned}
& \left(P_{w}\right)(h)-\left(T_{D}\right)(\operatorname{Cos} \theta)=0 \\
& T_{D}=(1.08)(2.438) /(\operatorname{Cos} 45) \\
& T_{D}=3.71 \mathrm{kN} / \mathrm{m} \quad(255 \mathrm{lbf} / \mathrm{ft})
\end{aligned}
$$

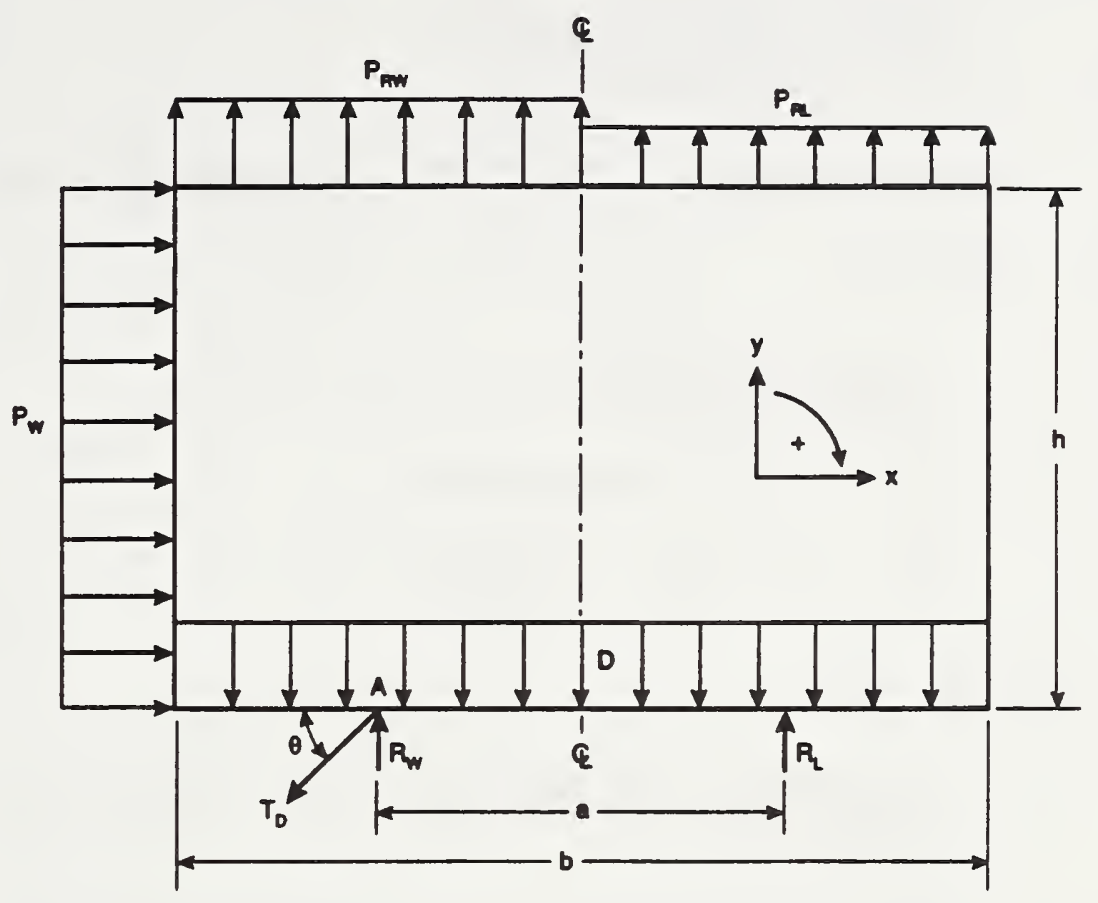

$$
\sum \mathrm{M}_{\mathrm{A}}=0
$$

$$
\begin{aligned}
\left(\mathrm{P}_{\mathrm{w}}\right)(\mathrm{h})(\mathrm{h} / 2)+\left(\mathrm{P}_{\mathrm{RW}}\right)(\mathrm{b} / 2)(\mathrm{b} / 4-\mathrm{a} / 2)-\left(\mathrm{P}_{\mathrm{RL}}\right)(\mathrm{b} / 2)(\mathrm{b} / 4+\mathrm{a} / 2)+(\mathrm{D})(\mathrm{b})(\mathrm{a} / 2) \\
-\left(\mathrm{R}_{\mathrm{L}}\right)(\mathrm{a})=0 \\
\mathrm{R}_{\mathrm{L}}=[(1.08)(2.438)(1.219)+(0.65)(2.133)(1.067-1.067)-(0.65)(2.133)(1.067 \\
\quad+1.067)+(1.20)(4.267)(1.067)] / 2.134 \\
\mathrm{R}_{\mathrm{L}}=2.68 \mathrm{kN} / \mathrm{m} \quad(183 \mathrm{lbf} / \mathrm{ft})
\end{aligned}
$$

$\sum F_{Y}=0$

$$
\begin{aligned}
& R_{W}+R_{L}+\left(P_{R W}\right)(b / 2)+\left(P_{R L}\right)(b / 2)-(D)(b)-\left(T_{D}\right)(\operatorname{Sin} \theta)=0 \\
& R_{W}=-2.68-(0.65)(2.133)-(0.65)(2.133)+(1.20)(4.267)+(3.71)(\operatorname{Sin} 45) \\
& R_{W}=2.30 \mathrm{kN} / \mathrm{m}(158 \mathrm{lbf} / \mathrm{ft})
\end{aligned}
$$


ASCE 7-88 Factored Wind Loads for $\mathrm{V}=40.2 \mathrm{~m} / \mathrm{s}(90 \mathrm{mph})$ :

(See Table 2)

$$
\begin{aligned}
& \mathrm{P}_{\mathrm{W}}=1.77 \mathrm{kPa}(37.0 \mathrm{psf}) \\
& \mathrm{P}_{\mathrm{RW}}=1.23 \mathrm{kPa}(25.6 \mathrm{psf}) \\
& \mathrm{P}_{\mathrm{RL}}=0.95 \mathrm{kPa}(19.9 \mathrm{psf})
\end{aligned}
$$

Factored dead load $=(0.9)(1.20)=1.08 \mathrm{kPa} \quad(22.5 \mathrm{psf})$

$$
\begin{aligned}
& \sum F_{X}=0 \\
& \left(P_{W}\right)(h)-\left(T_{D}\right)(\operatorname{Cos} \theta)=0 \\
& T_{D}=(1.77)(2.438) /(\operatorname{Cos} 45) \\
& T_{D}=6.12 \mathrm{kN} / \mathrm{m}(419 \mathrm{lbf} / \mathrm{ft}) \\
& \sum M_{A}=0 \\
& \left(P_{W}\right)(h)(h / 2)+\left(P_{R W}\right)(b / 2)(b / 4-\mathrm{a} / 2)-\left(P_{R L}\right)(b / 2)(b / 4+\mathrm{a} / 2)+(\mathrm{D})(\mathrm{b})(\mathrm{a} / 2) \\
& -\left(R_{L}\right)(\mathrm{a})=0 \\
& R_{L}=[(1.77)(2.438)(1.219)+(1.23)(2.133)(1.067-1.067)-(0.95)(2.133)(1.067 \\
& \quad+1.067)+(1.08)(4.267)(1.067)] / 2.134 \\
& R_{L}=2.74 \mathrm{kN} / \mathrm{m}(188 \mathrm{lbf} / \mathrm{ft}) \\
& \sum F_{Y}=0 \\
& R_{W}+R_{L}+\left(P_{R W}\right)(b / 2)+\left(P_{R L}\right)(b / 2)-(D)(b)-\left(T_{D}\right)(\operatorname{Sin} \theta)=0 \\
& R_{W}=-2.74-(1.23)(2.133)-(0.95)(2.133)+(1.08)(4.267)+(6.12)(\operatorname{Sin} 45) \\
& R_{W}=1.54 \mathrm{kN} / \mathrm{m}(105 \mathrm{lbf} / \mathrm{ft})
\end{aligned}
$$



